Western University Scholarship@Western

1983

\title{
The Informational Efficiency of Experimental Asset Markets
}

Daniel Friedman

Glenn W. Harrison

Jon W. Salmon

Follow this and additional works at: https://ir.lib.uwo.ca/economicsresrpt

Part of the Economics Commons

Citation of this paper:

Friedman, Daniel, Glenn W. Harrison, Jon W. Salmon. "The Informational Efficiency of Experimental Asset Markets." Department of Economics Research Reports, 8320. London, ON: Department of Economics, University of Western Ontario (1983). 
THE INFORMATIONAL EFFICIENCY OF EXPERTMENTAL ASSET MARKETS

by

Daniel Friedman

Glenn W. Harris on

Jon W. Salmon

September 1983

Friedman 1s Assistant Professor, Department of Eçonomics, UCLA; Harrison 1s Assistant Professor, Department of Economics, University of Western Ontario; Salmon is a Professional Economist with First Interstate Bancorp. We are Indebted to the Center for the Study of Futures Markets (Columbia University), the UCLA Department of Economics, and the Foundation for Research in Economics and Education (UCLA) for research support. Len-Kuo Hu provided excellent research assistance. 


\section{Introduction}

An informationally efficient market may be defined generally as one in which prices and allocations reflect all available information. This definition, coupled with certain assumptions as to what might constitute "all avallable information," leads to testable hypotheses about the behavior of asset markets. A fundamental difficulty in devising any test of such general efficient market hypotheses, however, is the specification of the relevant public and private information sets of traders. Given the absence of any consensus as to reasonable empirical specifications, tests of the hypotheses remain minimal or controversial. The primary objective of the present study is to provide a broad examination of the efficiency of experimental asset markets in which one may unambiguously identify the public and private information sets of traders. We focus on how market efficiency is affected by the presence of futures markets in settings that incorporate different types of uncertainty and inside information.

\subsection{Previous Literature}

In recent years theorists have become increasingly interested in the Informational role of prices in general and futures prices in particular; see, for Instance, Grossman [1977a,b] [1978], Bray [1981] and Grossman and St1g11tz [1976] [1980]. These theorists study a world in which information relevant to agents' intertemporal choices is dispersed throughout the economy. Under some conditions they find that competitive equilibrium prices will reveal everything that rational agents need to know to make choices which result in a fully efficient allocation. That is, the economy may achieve an allocation which is the same as that which would arise in a fictitious but otherwise similar economy in which each agent has access not only to his own personal information but also the personal information of each other agent. In this 
case prices are said to be perfect aggregators of information, and the market is considered strongly efficient. Competitive equilibria reflecting more limited information are referred to below as weakly efficient. 1

By way of illustration of the informational role of prices, Grossman [1977b] models a case in which spot prices alone do not perfectly aggregate information, but spot prices together with futures prices do. He argues that such information aggregation is a major function of futures markets. On the other hand Svensson [1976], among others, has argued that the existence of sequential trading opportunities and the simultaneous operation of spot and futures markets might lead to Pareto-inefficient outcomes.

Indeed there is a widely held belief (long reflected in public opinion, futures markets regulatory proposals, and the writings of economists such as Hardy [1940]) that organized futures markets display many features in common with gambling casinos and induce "unwarranted and undesirable" spot price fluctuations as volatile futures prices feed back to the spot market via storage and production decisions. Conventional empirical examinations of this controversy involve comparisons of spot price dispersion for time periods associated with, and then without, the presence of active futures trading in the good. The evidence for this class of tests has been noticeably mixed -see, for example, the results of Cox [1976] and his survey of other studies using this empirical approach. Besides the frequent lack of a theoretical model to tightly specify the tests and interpret the results, the long time periods involved suggest likely violations of the implied ceteris paribus

${ }^{1}$ In Fama [1970], weak form efficiency has a more precise definition (information sets consist only of past prices) than we employ here. We do employ Fama's distinction between semi-strong form efficiency (only public information) and strong form efficiency (all information, public and private, is reflected in prices). 
assumption.

The experimental approach offers the possibility of direct tests of market efficiency in which both market structure and individual information sets can be tightly controlled, so its recent popularity in the study of market efficiency issues is not surprising. The studies most relevant to our present concerns are Plott and Sunder [1982], Forsythe, Palfrey and Plott [1982a, 1982b], and Friedman, Harrison and Salmon [1983], hereafter referred to as PS, FPPa, FPPb, and FHS respectively. All of these studies employed a double oral auction for multiple units of a single good (the "asset") traded against cash. They differ primarily in their treatment of two critical elements of asset valuation: time and uncertainty.

PS focussed on uncertainty: their asset expired after a single period but had trader-specific marginal values that depended on an exogenous "state of nature." Trade typically occurred before the state of nature was revealed, although in some cases certain agents ("insiders") had advance information. They found that equilibrium prices usually revealed the inside information after several repetitions of the market, at least when that information was conclusive as to the true state of nature.

FPPa focussed on time: their asset derived its value from cash dividends paid over two periods, but each trader knew his own dividend schedule with certainty. Inasmuch as traders did not know others' schedules and therefore did not initially know what prices would be available to them, there existed an endogenous type of uncertainty that we refer to below as market uncertainty, in contrast with the exogenous event uncertainty of PS. FPPa found that asset prices approached "Rational Expectations" values after several repetitions of the market. 
The experiments reported in FPPb, which were conducted independently of those reported here, extended their previous design in two ways: they systematically examined the role of a futures market and (unlike the rest of the asset market studies, including our own) paid dividends as non-linear functions of asset holdings. Their main conclusions were that futures markets speeded convergence to Rational Expectations Equilibrium but at the same time increased spot price volatility.

\subsection{Current Approach}

FHS was a preliminary report on the first four of a set of nine ${ }^{2}$ experiments we conducted at UCLA in 1982. These experiments, discussed more fully in the next section, employed a three-perlod design that also allowed for event uncertainty and insider information, with or without futures markets. Within this design we are able to test the robustness of the PS and FPPa results, as well as obtain more refined characterizations of informational efficiency than has previously been possible in experimental asset markets.

FHS examined trader experience and the presence of futures markets as treatment variables in a setting with no event uncertainty. FHS confirms the importance of both variables in speeding convergence towards more Informationally efficient prices, and found that spot prices were less volatile when futures markets operated. We will comment later on this contrast with the FPPb finding.

\footnotetext{
2 The experiments listed in Table 1 below as \#1 and \#2 appeared in FHS as Experiments 3 and 4 . The other experiments 1isted in Table 1 have not previously been reported. We do not report here an experiment using inexperfenced subjects that was intended for training purposes.
} 
The present paper is our final report on this set of experiments. In the interest of brevity we will examine below only the six experiments that employed experienced subjects, ${ }^{3}$ and omit discussion of learning behavior and other issues raised in FHS that are tangential to informational efficiency. Following a description of our experimental design in Section 2, we provide a detailed numerical example in Section 3 to illustrate the operation of our markets and analytically derive several theoretical equilibria reflecting different amounts of information. We present our experimental results in Section 4 and conclusions in Section 5. Appendix 1 presents more fully the theory underlying our equilibrium concepts and Appendix 2 provides a detailed descriptive account of individual trader behavior in each experiment.

\section{Experimental Design}

\subsection{Common Experimental Design Features}

The participants in our experiments, referred to as traders, were recruited primarily from MBA classes at the UCLA Graduate School of Management -- as 1ikely a habitat for homo economus as we could think of. After distributing and reviewing the instruction sheets (available on request) we conducted double oral auction markets. Our traders were free to announce bid and offer prices and accept the bids or offers of others providing they did not violate any budget constraint, as discussed below. Transacted prices were publicly recorded. The assets traded were called certificates; they yielded returns, called dividends, to traders who possessed them at the end of each

3 We regard an experiment as involving experienced subjects if at least three-quarters of the current participants have been subjects in a previous 3period experimental asset market. 
trading period.

Each experiment consisted of a series of "Market Years", which can be thought of as Hicksian weeks. Within each Market Year there were three trading periods, referred to as perlods A, B and C. Each trading period lasted for five minutes (real time) and each trader could buy or sell one certificate at a time. Lot sales, short sales (i.e., short spot positions and "naked" short futures positions) and negative cash positions were prohibited. 4 At the beginning of each Market Year each trader was endowed with two certificates and an interest-free loan of twenty dollars. The loans were sufficiently large that the liquidity constraint was never an impediment to trade.

Incentives for exchange among traders were provided by varying the per certificate dividends across individuals as well as across periods. There were three trader types, with Individuals randomly assigned to each group; Table 1 provides details of the parameterizations for each experiment. The underlying period-specific certificate returns were identical across market years - identical in the aggregate and for each individual. 5 Thus the markets were repetitively stationary from Year to Year. Note that traders were not informed of this stationarity; they had to learn about it in "real time". Each Individual was carefully monitored so that his/her private dividend profile was not observed by any other trader. Possibilities for explicit or implicit collusion were effectively nil.

\footnotetext{
${ }^{4}$ Plott and Sunder [1983] is the first study to allow short (spot) positions within a trading period. They employ a simple and apparently effective penalty on any trader short at the end of any period (viz., a fixed pecuniary penalty plus the requirement that the trader implicitly cover himself at the highest transaction price during the period).

${ }^{5} \mathrm{~A}$ minor exception in Year 5 of Experiment 2 is noted in Table 1.
} 
TABLE 1

Induced Experimental Market Parameters

\begin{tabular}{|c|c|c|c|c|c|c|c|c|c|}
\hline \multirow{2}{*}{$\frac{\text { Experiment }}{1}$} & $\begin{array}{c}\text { Market } \\
\text { Institution }\end{array}$ & \multicolumn{2}{|c|}{ Agents } & \multicolumn{4}{|c|}{ Dividend Profile } & & \\
\hline & $\begin{array}{l}\text { Market Uncertainty } \\
\text { No Futures }\end{array}$ & $\begin{array}{l}\text { I } \\
\text { II } \\
\text { III }\end{array}$ & $\begin{array}{l}1,3,6 \\
4,7,9 \\
2,5,8\end{array}$ & $\begin{array}{l}0.45 \\
0.70 \\
0.10\end{array}$ & $\begin{array}{l}0.45 \\
0.30 \\
0.30\end{array}$ & & $\begin{array}{l}45 \\
10 \\
70\end{array}$ & & \\
\hline \multirow[t]{3}{*}{2} & $\begin{array}{l}\text { Market Uncertainty } \\
\text { Futures }\end{array}$ & $\begin{array}{l}\text { I } \\
\text { II } \\
\text { III }\end{array}$ & $\begin{array}{l}5,7,9 \\
1,3,6 \\
2,4,8\end{array}$ & $\begin{array}{l}0.75 \\
0.40 \\
0.15\end{array}$ & $\begin{array}{l}0.20 \\
0.45 \\
0.30\end{array}$ & & $\begin{array}{l}10 \\
45 \\
80\end{array}$ & & \\
\hline & & & & \multicolumn{2}{|c|}{ A } & \multicolumn{2}{|c|}{ B } & \multicolumn{2}{|c|}{ C } \\
\hline & & & & $\bar{X}$ & $\bar{Y}$ & $\bar{X}$ & $\mathrm{Y}$ & $\bar{X}$ & $\bar{Y}$ \\
\hline 3 & $\begin{array}{l}\text { Event Uncertainty } \\
\text { No Futures }\end{array}$ & $\begin{array}{l}\text { I } \\
\text { II } \\
\text { III }\end{array}$ & $\begin{array}{l}2,7,9 \\
1,4,6 \\
3,5,8\end{array}$ & $\begin{array}{l}.30 \\
.15 \\
.40\end{array}$ & $\begin{array}{l}.60 \\
.15 \\
.30\end{array}$ & $\begin{array}{l}.25 \\
.70 \\
.53\end{array}$ & $\begin{array}{l}.53 \\
.70 \\
.40\end{array}$ & $\begin{array}{l}.35 \\
.20 \\
.70\end{array}$ & $\begin{array}{l}.70 \\
.20 \\
.55\end{array}$ \\
\hline 4 & $\begin{array}{l}\text { Event Uncertainty } \\
\text { Futures }\end{array}$ & $\begin{array}{l}\text { I } \\
\text { II } \\
\text { III }\end{array}$ & $\begin{array}{l}1,6,9 \\
3,5,8 \\
2,4,7\end{array}$ & $\begin{array}{l}.25 \\
.20 \\
.50\end{array}$ & $\begin{array}{l}.75 \\
.20 \\
.30\end{array}$ & $\begin{array}{l}.10 \\
.80 \\
.60\end{array}$ & $\begin{array}{l}.60 \\
.80 \\
.30\end{array}$ & $\begin{array}{r}.50 \\
.30 \\
1.00\end{array}$ & $\begin{array}{r}1.00 \\
.30 \\
.70\end{array}$ \\
\hline 5 & $\begin{array}{l}\text { Insider Uncertainty } \\
\text { No Futures }\end{array}$ & $\begin{array}{l}\text { I } \\
\text { II } \\
\text { III }\end{array}$ & $\begin{array}{l}2,5 *, 6 \\
1,8,9 * \\
3,4,7 *\end{array}$ & $\begin{array}{l}.50 \\
.25 \\
.20\end{array}$ & $\begin{array}{l}.30 \\
.25 \\
.40\end{array}$ & $\begin{array}{l}.35 \\
.45 \\
.30\end{array}$ & $\begin{array}{l}.30 \\
.60 \\
.50\end{array}$ & $\begin{array}{r}.50 \\
.40 \\
.30\end{array}$ & $\begin{array}{l}.30 \\
.20 \\
.80\end{array}$ \\
\hline 6 & $\begin{array}{l}\text { Insider Uncertainty } \\
\text { Futures }\end{array}$ & $\begin{array}{l}\text { I } \\
\text { II } \\
\text { III }\end{array}$ & $\begin{array}{l}1,4 *, 9 \\
3,5,7 * \\
2 *, 6,8\end{array}$ & $\begin{array}{l}.45 \\
.15 \\
.20\end{array}$ & $\begin{array}{l}.30 \\
.50 \\
.40\end{array}$ & $\begin{array}{l}.35 \\
.30 \\
.40\end{array}$ & $\begin{array}{l}.35 \\
.60 \\
.45\end{array}$ & $\begin{array}{l}.35 \\
.45 \\
.30\end{array}$ & $\begin{array}{l}.25 \\
.30 \\
.70\end{array}$ \\
\hline
\end{tabular}

NOTES: In Year 5 of Experiment 2 a random reassignment of agents to trader type occurred; investor type I consisted of Agents 1, 3 and 5; type II of Agents 4,6 and 8; and type III of Agents 2, 7 and 9. The parameters shown here pertain to all other Market Years. In Experiments 5 and 6 an asterisk beside an Agent ID\# denotes insiders. In Year 5 of Experiment 5 there was a change in the agents of each type that were insiders: agents $\# 2,1,4$ were the insiders for that Year only. 
To motivate the experimental set up one can think of the traders as grain merchants trading in warehouse certificates which have a par value of zero but provide each trader with a finite time profile of convenience yields. Of course, in our experiments traders actually received a cash "dividend" for each certificate held at the end of each trading period, and the certificates expired after the Market Year ended.

In Experiment 1 trading consisted of an immediate exchange of cash for certificates at accepted bid or offer prices (i.e., spot transactions only). In Experiment 2 we permitted futures transactions as well. The futures contract consisted of the delivery of a certificate in period $C$. Futures contracts as well as spot contracts could be written in both period $A$ and period B. In periods $A$ and $B$ dividends were paid as usual for each (spot) certificate held at the end of that period. No transactions were allowed in period C In Experiment 2, but deliveries previously contracted for were performed. An individual with a net long (short) futures position was required to take (make) delivery of the certificates, and then perfod $C$ dividends distributed. A natural interpretation of period $C$ is that it corresponds to the day after the last trading day in the delivery month of a futures contract. Note that an agent had ample opportunity to offset futures positions during periods $A$ and $B$. However, because of the restriction on short sales, agents' short futures positions were limited to the quantity of inventoried spot certificates at any point in time. For a given net short position an agent's spot sales were also constrained.

In all experiments traders were given a small trading commission of one cent per transaction. Such commissions are a standard feature of most experimental market studies; the usual rationale for their inclusion is to overcome subjective transaction costs which might be especially relevant when 
transacted prices are very close to a market-clearing price. At the end of each experiment we paid our traders in cash for all profits accrued from dividends and trading.

\subsection{The Event and Insider Uncertainty Designs}

The distinguishing feature of Experiments 3 and 4 is that each trader's dividend profile is specific to a "state of nature." Two different states, called $X$ and $Y$, were possible. At the beginning of the Experiment all traders were told that we would flip a fair coln at the end of each Period A trading round, and if the coin came up heads then state $X$ occurs and if the coin showed tails then state $Y$ occurs for that Market Year. Thus, at the beginning of Period A all traders had common prior beliefs about the ultimate realization of states $X$ or $Y$, based on public knowledge that each state had a $50 \%$ probability of occurring for each Market Year, and trading during Period A occured under this well-defined event uncertainty. The uncertainty was then resolved as advertised, ${ }^{6}$ so Periods $B$ and $C$ represented posterior trading rounds in which agents had the opportunity to revise their portfolio of certificate holdings under conditions of no event uncertainty, as in the previous experimental design. The futures market in Experiment 4 operated in the same manner as in Experiment 2, except that in Period A trading for Period $C$ certificates was subject to the same event uncertainty as spot trading.

The Insider Uncertainty design built upon the Event Uncertainty design. The distinguishing feature of Experiments 5 and 6 was that one trader of each trader type was randomly selected to receive conclusive information about

${ }^{6}$ Plott and Sunder [1983] introduce the idea of actually announcing states of nature from a predetermined sequence. Although there is no evidence that this occurred in their experiments, we were concerned that traders not begin to "second-guess" the sequence of events. 
which state would occur before Period A trading took place for each Market Year. ${ }^{7}$ This was accomplished by the experimenter leaving the room before the start of the experiment, flipping a coin and then writing down the results on 3 out of 9 cards. Cards which read either "No Information" or "State _" were put Into envelopes and passed out to the traders. Thus, the six non-insiders did not have prior knowledge about the 1dentity of the insiders. These experiments then proceeded in the same manner as the event uncertainty experiments.

\section{Theoretical Analysis and Predictions}

\subsection{An Example}

A concrete numerical example will help the reader develop an intuition for how our markets work, and reduce the need for a lengthy abstract discussion in the next few subsections. Let us begin with the hypothetical dividend profile and agent assignment shown in Table 2.

Consider the strategic opportunities available to (say) Agent $\# 9$ in period C - the last trading period of a market year with spot trading only. Since he has a dividend profile of type III, he will recelve $\$ 0.70$ for each certificate he owns at the end of the period's trading, and the certificates have no further value to him or anyone else. Hence, $\$ 0.70$ represents his "reservation price": he will profit by any purchases he can make at a lower price and sales at any higher price. Agent $\$ 9$ has no direct knowledge of the

7 Inconclusive inside information (a series of "clues" as to the true state) has been examined experimentally in Experiment 1 of PS. They find that convergence to the rational expectations equilibrium is much slower in this case compared to experiments with conclusive inside information. Plott and Sunder [1983] also implement inconclusive inside information (no trader knows the true state, but their pooled information set is conclusive). 
TABLE 2

Hypothetical Experimental Market Parameters

\begin{tabular}{|c|c|c|c|c|}
\hline \multicolumn{2}{|c|}{ AGENTS } & \multicolumn{3}{|c|}{ DIVIDEND PROFILE } \\
\hline Type & ID \# & Period A & Period B & Period C \\
\hline I & $1,2,3$ & 0.45 & 0.45 & 0.45 \\
\hline II & $4,5,6$ & 0.70 & 0.30 & 0.10 \\
\hline III & $7,8,9$ & 0.10 & 0.30 & 0.70 \\
\hline
\end{tabular}


reservation prices of other agents. He will soon discover, however, that nobody can afford to outbid him, while he can't undersell anyone. Hence, he may find that if he actively bids and aggressively accepts offers he will acquire certificates at prices below his reservation price - but probably not much below and not for long. Agents $\$ 7$ and $\$ 8$ also have a reservation price of $\$ 0.70$, so if either one of them notices that \#9 is snapping up certificates at (say) $\$ 0.60$ one or both are likely to begin to bid (say) $\$ 0.62$ or $\$ 0.65$ in an attempt to acquire the certificates. This process may be expected to raise the transacted price to $\$ 0.70$ in fairly short order (recall the one cent trading commission) as long as at least two of the type III traders actively attempt to buy up "cheap" certificates. Evidently $\$ 0.70$, the highest reservation price, ${ }^{8}$ is the equilibrium price for period $C$, and the corresponding allocation Involves all certificates being held by the type III agents. Presumably the most aggressive bidder among them gets the lion's share.

Now consider trading in the prior period B. At this point our agent $\$ 9$ knows a certificate will yield him at least $\$ 0.30$ (current dividend) $+\$ 0.70$ (period $C$ dividend) $=\$ 1.00$, and possibly more if he were able to resell in the current period at a price above $\$ 1.00$ or in period $C$ at a price above \$0.70. We are unable to determine his reservation price in this period without knowing his attitude to risk and the probabilities he assigns to these resale possibilities, but we do know that it is bounded below by his "security

\footnotetext{
8More specifically, the second highest reservation price among the nine traders, which in the current instance happens to equal the first and third highest since there are three agents of type III. See Vickrey [1961] for an explanation of the familiar pricing result that the winning bid is the second highest reservation price. Friedman [1982] and Friedman and Harrison [1983] formalize the logic and Bayesian computation of these reservation prices for models of the price formation process in experimental asset markets.
} 
level" of $\$ 1.00$. Agent $\# 1$ is in a more interesting position: he has a lower security level $(\$ 0.45+\$ 0.45=\$ 0.90)$, but if he has seen this market operate for several Market Years he may become quite confident of his ability to resell in period $\mathrm{C}$ at $\$ 0.70$. In this case his reservation price will be approximately $\$ 0.45$ (current dividend) $+\$ 0.70$ (resale value in period $C$ ) $=\$ 1.15$, so he is likely, at least in later Market Years, to outbid \#9 and the other type III agents. Once again the price should be bid up to the highest reservation price among the agents of type I if the others (\#2 and \#3) also come to realize (either independently or through noticing \#1's "windfall profits") that certificates might be worth more than $\$ 1.00$ to them in period B. Consequently, the period B price should settle somewhere between $\$ 1.00$ (the highest security level) and $\$ 1.15$ (highest "rational" reservation price), with the price rising towards the higher value as agents accumulate experience over the years. All certificates should be held by type I traders for choosing prices in excess of $\$ 1.00$.

Similar considerations apply to period A trading. The highest security level belongs to type I traders $(\$ 0.45+\$ 0.45+\$ 0.45=\$ 1.35)$, but if type II traders begin to anticipate the ability to resell in period $B$ at a price approaching $\$ 1.15$ their reservation price would be near $\$ 0.70+\$ 1.15$ $=\$ 1.85$. Over the Years, learning may allow the closing period A price to rise from $\$ 1.35$ to nearly this value.

Suppose now that the data in Table 3 refer to an experiment in which futures trading is permitted, and consider the strategic possibilities available to agent $\# 1$ in Period B. He personally would be willing to bid at most $\$ 0.45$ for futures contracts (1.e., period C delivery of certificates), but for reasons discussed above it seems likely that agents of type III will bid up the price of this contract to $\$ 0.70$. With a currently quoted futures 
price of $\$ 0.70$ agent $\# 1$ now has a security level for spot transactions of $\$ 1.15$, not $\$ 0.90$ as before: for each certificate he acquires he can sti11 earn his current period dividend of $\$ 0.45$ while "locking in" an additional $\$ 0.70$ return by selling a futures contract. He need not guess, as was the case in the spot-only market, as to 1 ts subsequent resale value. Hence a period B spot price of $\$ 1.15$ and a futures price of $\$ 0.70$ can arise from information directly available to the agents. Note that spot trading in period $C$ should be redundant, given the operation of the futures market in prior periods.

The strategic opportunities in period A are quite rich. The opportunities discussed above still obtain, but the futures price provides additional information. If the futures price for period $C$ delivery of certificates converges to $\$ 0.70$ in period $A$, then agents of type II will have a security level of $\$ 1.70$ ( $\$ 0.70$ current dividends $+\$ 0.30$ period $B$ dividends $+\$ 0.70$ proceeds from the futures transaction). Hence we may expect that these agents (together with type I agents) will more quickly bid up spot prices when the futures market is active.

So far we have only dealt with the Market Uncertainty design of Experiments 1 and 2. To see the effect of Event Uncertainty suppose the parameters of Table 2 apply to state $X$, and for simplicity assume that state $Y$ dividends are each $10 \oint$ higher than those for state $X$. Inasmuch as all traders know whether state $X$ or state $Y$ obtains before Period $B$ opens, there are no new considerations introduced into the previous discussion of Period C and Period B trading. However, consider the Period A problem facing our favorite agent, \#9, in Experiment 3 (spot trading only). If he knew that state $X$ would eventuate his security level would be $\$ 0.10+0.30+0.70=$ $\$ 1.10$, but 1 would be $\$ 0.20+0.40+0.80=\$ 1.40$ in state $Y$. Given that 
his priors have been induced as $0.5 / 0.5$ over the two states we may suppose that his "effective" security level is $\$ 1.25$ (or a little less with risk aversion). If trader $\$ 9$ and his fellow traders initially consider only "buy and hold" strategles (1.e., they do not speculate on being able to resell or repurchase at favorable prices in subsequent Periods), the arguments advanced above lead us to predict a market price equal to the highest such "effective" security level, which sti1l belongs to type I agents $(\$ 1.35(.5)+\$ 1.65(.5)$ $=\$ 1.50)$. On the other hand, once traders gain experience with trading opportunities in Periods $B$ and $C$ in both states of nature they may be willing to consider expected trading opportunities in forming reservation prices, in which case Perlod A prices will generally tend to rise in later Market Years. How far? Given a maximum reservation price of $\$ 1.85$ in state $X$ (as argued above) and $\$ 2.15$ in state $Y$, an upper bound of $\$ 2.00=\$ 1.85(.5)+$ $\$ 2.15(.5)$ is defined.

Similar considerations apply when futures markets exist, as in Experiment 4. Given our hypothetical parameters we would expect to see futures trading in Period A yield a price for Period C certificates of at least $\$ 0.70$ (the maximum security level in the least favorable state, $X$ ) and probably closer to $\$ 0.75=\$ 0.70(.5)+\$ 0.80(.5)$, the "effective" security level. Once the futures price has stabllized, spot prices in Perlod A should reflect the higher security level and thus converge more rapidly to the upper bound of \$2.00. It is interesting to observe that fairly complicated trading plans are of ten required to support these higher Period A spot prices; in the current hypothetical example Type II traders who purchase spot certificates at a Period A price near $\$ 2.00$ probably also hedge (sell futures) at the same time, and plan in Period B to sell spot while offsetting their futures positions. In the actual experiments contingencles based on the state of nature are 
important, and effictent plans can become even more complex.

We close this discussion with a few observations regarding insider information. Once again, only Period A trading is affected; to the extent that the Insiders' information leaks out, the "event uncertainty" becomes irrelevant. Thus it is not clear a priori whether the state-specific or "effective" reservation prices are more appropriate, but we should often be able to determine from transactions data whether or not a leak occurred. 3.2 A Theoretical Model

A very brief sketch of our theoretical model of experimental markets is required to define and justify our predicted market outcomes. A more complete account can be found in Appendix 1.

Agents, or traders, indexed $i=1, \ldots, 9$, are classified into types ( $I$, II or III) according to ( 1 ) their endowments $x_{1}(0)$ of cash and period-dated assets, with periods indexed $k=1,2,3$; and (11) their preferences, determined by specific per-certificate dividends, $d_{i}^{k}(z)$, where $z=x$ or $Y$ denotes the state of nature. 9 We assume each agent $i$ will try to transact so as to acquire final holdings $x_{1}(T)$ that maximize end-of-year wealth,

$$
w_{1}(T, z)=d_{1}(z) \cdot x_{1}(T) \equiv x_{1}^{0}(T)+\sum_{k=1}^{3} d_{1}^{k}(z) x_{1}^{k}(T) \equiv \text { cash + dividends. }
$$

Of course, trading typically occurs under incomplete and possibly asymmetric information regarding (a) the state of nature, $z$, and (b) the trading opportunities contingent on $z$. The strongest notion of informational efficiency is based on the idea that the market has somehow disseminated

${ }^{9}$ We make the convention that $z=X$ with certainty in Experiments 1 and 2 , and often will drop the index $z$ when discussing these experiments. 
perfect information regarding both (a) and (b). We refer to this case as Perfect Foresight (PF); the equilibrium is then the ordinary (complete markets, perfect information) Competitive Equilibrium in which all

certificates are held by traders of the highest dividend type in each period and prices reflect these dividends. That is, given that the state of nature is (or will be revealed as) $z$, the PF-prices are:

$$
\begin{aligned}
& p(A \mid P F, z)=\sum_{k=1}^{3} \max _{i} d_{i}^{k}(z) \text { in period } A, \\
& p(B \mid P F, z)=\sum_{k=2}^{3} \max _{i} d_{i}^{k}(z) \text { in period } B \text {, and } \\
& p(C \mid P F, z)=\max _{1} d_{i}^{3}(z) \text { in period } C .
\end{aligned}
$$

The corresponding allocations $x_{1}^{k}$ are 0 unless $i$ belongs to the type ${ }^{10}$ for which $d_{1}^{k}(z)$ is maximal, $k=1$ for Period $A, k=2$ for Period $B$, and $k=$ 3 for Period C. For Experiments 1, 2, 5 and 6, this PF equilibrium corresponds directly to the popular notion of strong-form efficient prices.

In Experiments 3 and 4 no information regarding the state of the world is avallable during Period A trading. Hence the strongest available concept of informational efficiency must be based only on the contingent trading opportunities (b), together with the induced prior probabilities. We refer to this case as Uninformed Rational Expectations (URE): assuming all agents are risk-neutral, know all the contingent (PF) prices, and share the

${ }^{10}$ Inasmuch as the distribution of certificates is indeterminate among those of the given (maximal) type, the equilibrium is not unique. Note, however, that equilibrium prices are unique because the induced preferences are additively separable $=$ cf. Arrow and Hahn [1971; Ch. 9]. 
probabilities $\pi(z)$ over states of the world $z \varepsilon Z=\{X, Y\}$, one can show (see Appendix 1) that the equilibrium spot price in Period A is

Likewise,

$$
p(A \mid U R E)=\max _{i} \sum_{z \in Z} \pi(z)\left[d_{i}^{1}(z)+p(B \mid P F, z)\right] .
$$

$$
p(C \mid U R E)=\sum_{z \varepsilon Z} \pi(z) p(C \mid P H, z)
$$

is the equilibrium futures price in Period A under the same circumstances. As usual, the corresponding Period A allocations for spot certificates are zero for non-maximal 1 and indeterminate among 1 in the maximal type. Futures allocations in Period $A$ are completely indeterminate; indeed under current assumptions the- Period A futures market is redundant, given the opportunity in Period B to readjust positions before Period $C$ dividends are distributed. It is interesting to note that in Experiments 5 and 6 both URE and PF equilibria are relevant, with URE in this case corresponding to the notion of semi-strong informational efficiency (prices reflect all public, but not insider, information).

In the numerical example of the previous subsection PF or URE prices were regarded as upper bounds that might be approached as traders acquired type (b) Information. Since traders possess no reliable information of this sort at the beginning of each Experiment, it is useful to define another benchmark equilibrium corresponding to weaker concepts of information efficiency. We refer to the case in which traders know the state of the world and their own personal dividend profiles but not their trading opportunities in subsequent Periods as Private Information (PI). There is an incompletemarkets, incomplete-information Competitive Equilibrium (in which agents do not use equilibrium prices as a supplementary source of information) under 
these circumstances whose contingent prices $^{11}$ are:

$$
\begin{aligned}
& p(A \mid P I, z)=\max _{1} \sum_{k=1}^{3} d_{i}^{k}(z), \\
& p(B \mid P I, z)=\max _{1} \sum_{k=z}^{3} d_{1}^{k}(z), \text { and } \\
& p(C \mid P I, z)=\max _{1} d_{1}^{3}(z) .
\end{aligned}
$$

Two possible modifications to the Period A PI prices should be mentioned briefly. First, if futures markets operate then markets are not quite so incomplete and a slightly stronger notion (still denoted PI) is appropriate:

$$
p(A \mid P I, z)=p(C \mid P I, z)+\max _{i} \sum_{k=1}^{2} d_{1}^{k}(z),
$$

where $p(C \mid P I, z)=\max d_{1}^{k}(z)$ is, of course, also the equilibrium contingent futures price in Period A. Note that the futures market is not redundant under PI-assumptions.

Second, if agents do not know $z$ in Period A but share firm priors $\pi(z)$ we may define the Expected Private Information (EPI) equilibrium price as

$$
p(A \mid E P I)=\max _{i} \sum_{k=1}^{3} \sum_{z \varepsilon Z} \pi(z) d_{i}^{k}(z) .
$$

${ }^{11}$ As usual, the corresponding allocations are zero except for 1 of the type for which the indicated maximum is achieved. This will often be taken for granted in later discussions. 
An interpretation of EPI based on "effective security levels" was offered in the previous subsection.

For convenient reference we list and compute the applicable equilibria for each Experiment in Table 3.

The relevance of all these equilibrium concepts may not be immediately apparent to the reader. Our markets are not populated by large numbers of price-taking agents, nor is Walrasian "recontracting" allowed, so the conventional theoretical basis for Competitive Equilibrium is absent. Instead, our double auction institution creates a very complex, continuoustime extensive-form game of incomplete information for our set of nine agents. Friedman [1982] shows how some apparently mild consistency assumptions can lead to a tractable analysis of single-period games of this type, and In Appendix 1 we extend that analysis to three-period asset markets. The first main result is that PI final allocations and prices can be supported by a certain Noncooperative Equilibrium in strategies contingent on very limited information. After noting that agents have more public Information In later Market Years since they have been able to observe market prices in all Perlods, we show that PF (or URE) equilibria can be supported as Noncooperative equilibria in strategies based on information that is eventually made public by the double auction process.

\subsection{Predictions from the Theory}

3.3.1 Convergence to Stronger-form Informational Efficiency

Our first principal prediction is that prices and allocations in each experiment more nearly approach the stronger-form equilibrium values in later Market Years. The reason, of course, is that traders acquire better information as to (state-contingent) trading opportunities through their actual trades, and this information becomes reflected in the prices. Although 
Experiment 1: Market Uncertainty with No Futures Market

$$
\begin{aligned}
& P(A \mid P I)=\max _{1} \sum_{k=1}^{3} d_{1}^{k}=\$ 1.35 \quad[I] \\
& P(B \mid P I)=\max _{i} \sum_{k=1}^{3} d_{1}^{k}=\$ 1.00 \text { [III] } \\
& P(C \mid P I)=\max _{1} d_{1}^{3}=\$ 0.70 \quad \text { [III] }
\end{aligned}
$$

Exper1ment 2: Market Uncertainty with a Futures Market

$$
\begin{aligned}
& P(A \mid P I)=P(C \mid P I)+\max _{1}\left(d_{1}^{1}+d_{1}^{2}\right)=\$ 1.75 \\
& P(B \mid P I)=P(C \mid P I)+\max _{1} d_{1}^{2}=\$ 1.25 \\
& P(C \mid P I)=\max _{1} d_{1}^{3}=\$ 0.80
\end{aligned}
$$

Experiment 3: Event Uncertainty with No Futures Market

$$
\begin{aligned}
P(A \mid E P I) & =\max _{1}\left[\sum_{k=1}^{3} \sum_{z \varepsilon Z} \pi(z) d_{1}^{k}(z)\right]=\$ 1.44 \\
P(B \mid P I, z) & =\max _{1} \sum_{k=2}^{3} d_{1}^{k}(z)=\$ 1.231_{z=Y}^{z}=X \\
P(C \mid P I, z) & =\max _{1} d_{1}^{3}(z)=\$ 0.701_{z}=X
\end{aligned}
$$

$$
\begin{aligned}
& P(A \mid P F)=\sum_{k=1}^{3} \underset{1}{\max } d_{1}^{k}=\$ 1.85 \quad[I I] \\
& P(B \mid P F)=\sum_{k=2}^{3} \sum_{1}^{\max } d_{1}^{k}=\$ 1.15 \quad[I] \\
& P(C \mid P F)=\max _{1} d_{1}^{3}=\$ 0.70 \quad \text { [III] }
\end{aligned}
$$$$
P(A \mid P F)=\sum_{k=1}^{3} \max _{1} d_{1}^{k}=\$ 2.00 \quad[I]
$$$$
P(B \mid P F)=\sum_{k=2}^{3} \max _{1} d_{1}^{k}=\$ 1.25 \quad[I I]
$$$$
P(C \mid P F)=\max d_{1}^{3}=\$ 0.80 \quad[\text { III] }
$$

$p(A \mid U R E)=\max _{1}\left\{\sum_{z \varepsilon Z} \pi(z)\left\{d_{i}^{l}(z)+p(B \mid P F, z)\right]\right\}=\$ 1.85$

$P(B \mid P F, z)=\max _{1} d_{1}^{2}(z)+P(C \mid P F, z)=\$ 1.40(X$ or $Y)$

$p(C \mid P F, z)=\max _{1} d_{1}^{3}(z)=\$ 0.701_{z=Y}^{2}=X$

Experiment 4: Event Uncertainty with a Futures Market

$$
\begin{aligned}
& p(A \mid E P I)=p(C \mid E P I)+\max _{1}\left[\sum_{k=i}^{2} \sum_{z \in Z} \pi(z) d_{1}^{k}(z)\right]-\$ 1.85[I I] p(A \mid U R E)=\max _{1}\left[\sum_{z \varepsilon Z} \pi(z)\left[d_{1}^{l}(z)+p(B \mid P F, z)\right]\right\}=\$ 2.30 \text { [I] }
\end{aligned}
$$

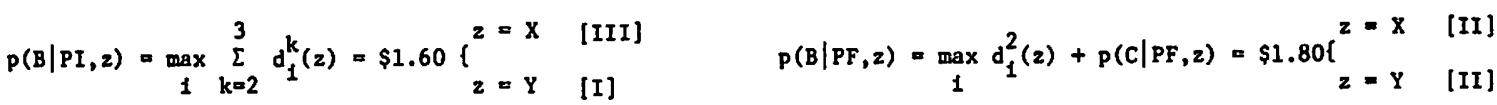

$$
\begin{aligned}
& P(C \mid E P I)=\max _{1}\left[\sum_{z \varepsilon z} \pi(z) d_{1}^{3}(z)\right]=\$ 0.85 \quad \text { [III] } \quad P(C \mid \text { URE })=\sum_{2 E Z} \pi(z) p(C \mid P F, z)=\$ 1.00 \quad \text { [I, II, or III] }
\end{aligned}
$$

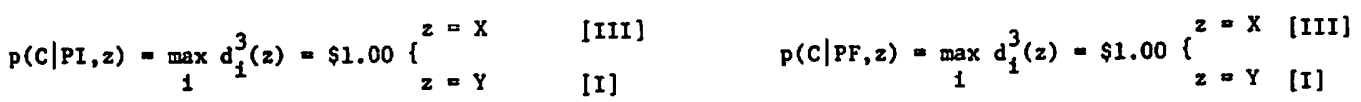

Experiment 5: Ins1der Uncertainty with No Futures Market

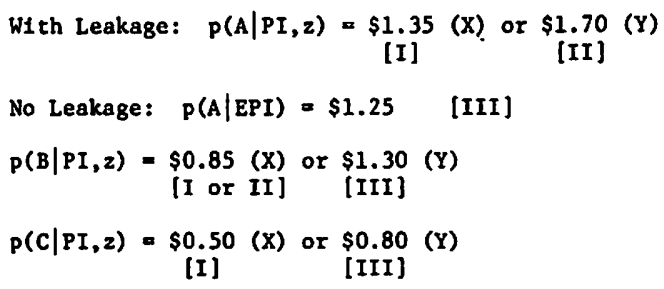

Experiment 6: Insider Uncertainty with a Futures Market

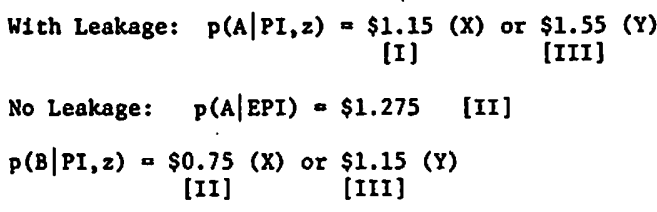

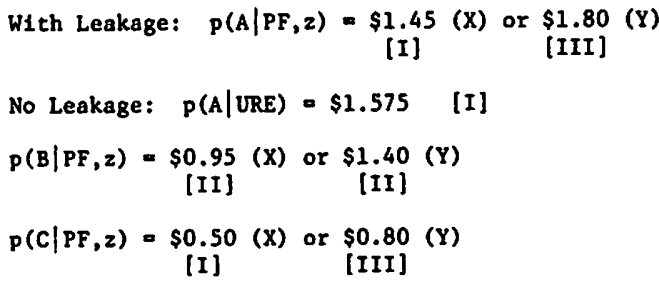


theorists may differ on the details of the process, Its existence is generally uncontroversial, and virtually all experimental double auction markets display a powerful tendency to approach full efficiency under stationary repetition. 12

This first prediction does involve one controversial point in connection with our Experiments 5 and 6 . Is the semi-strong form of informational efficiency (URE) or the strong form (PF) the better predictor of behavior in later Market Years? Given that we have only one Insider of each type competition may not force the inside information into the open; indeed, we know of no serious theoretical argument for PF-efficiency for this case. 13 On the other hand, those economists with great faith in the "wisdom of the market" would probably predict this strongest-form efficiency even without the theory.

\subsubsection{The Informational Role of Futures Markets}

Our second prediction is that the presence of a futures market speeds the approach to stronger-form equilibrium and reduces the volatility of transacted spot prices. The theoretical justification is clear: markets are more nearly complete and more information is avallable when futures markets are open. To drive this point home, consider the minimum time required for PF (or URE) outcomes to emerge from an ideal learning process. In the spot-only, noevent-uncertainty design of Experiment 1, traders should ideally observe $p(C \mid P F)=p(C \mid P I)=\max _{1} d_{1}^{3}$ at the end of the first market year (see Appendix

12 Harrison, Smith and Williams [1983] present experimental evidence for perishables that convergence to equilibrium in double auctions is sluggish in the absence of market stationarity, and that deviations from equilibrium are often sustained and severe. Friedman and Harrison [1983] present evidence for single-period asset markets that convergence to equilibrium is more rapid in the absence of stationarity.

${ }^{13}$ Appendix 1 sketches an argument for at least URE efficiency. 
1). If they all jump to the conclusion that $p(C \mid P F)$ will always obtain in Period $C$ of subsequent market years, believe that other traders have jumped to the same conclusion and trade accordingly, then they will be correct. Furthermore, in this case the same sort of argument shows that period B prices will close at $p(B \mid P F)$ in the following repetition (Year 2). Similarly, closing prices in Period $A$ of Year 3 can reach $p(A \mid P F)$ if agents count on trading at $p(B \mid P F)$ in the subsequent period. Hence the $P F$ outcome is possible in Year 4 for Experiment 1.

The existence of futures markets can shorten this learning process by a Year, since $p(B \mid P I)=p(B \mid P F)$ if futures are traded in Period $B$. In the case of event uncertainty one must observe $p(C \mid P F, z)$ and $p(B \mid P F, z)$ for each $z \in Z$ before $p(A \mid U R E)$ can emerge, so the minimum learning time is $2(\# Z)+1$ Years if there is no futures market (Experiment 3), and $z_{Z}+1$ if there is a futures market (Experiment 4). The presence of insiders would not lessen the theoretical minimum learning time, although it could lessen (or increase, since noninsiders may be more cautious) the actual learning time. As noted in our literature survey, the prediction that futures markets are stabilizing and speed convergence to informationally efficient equilibria is not without controversy. The contrary argument by Svensson [1976] for destabilization employs the assumption that agents may unanimously hold incorrect point expectations regarding subsequent prices, and therefore its relevance to our experimental markets is questionable. However, the popular version of the contrary view, that speculation in futures markets introduces "noise" Into the price system, may have a counterpart in our experiments. Our traders face a more complex environment when futures trading is permitted: they must keep track of two prices instead of one in each trading period, the total trading time in each Market Year is less because there are two trading 
periods instead of three, and more complicated buylng/selling decisions may be required because there are four "markets" (spot and futures in Periods A and B) Instead of three. Hence they are more likely to suffer from "Information overload" and confusion, and market efficiency could thereby be impaired (see Grether and Wilde [1982]).

\section{Experimental Results}

Our raw data provide an embarrassment of riches: for spot and (where applicable) futures, in each Period of each Market Year in each Experiment we have a long sequence of bid and ask prices, accepted or unaccepted, identified by trader. Each such sequence typically contains 10-50 entries. Such detail is critical when studying the real-time process of learning behavior and price formation as in Easley and Ledyard [1983], Friedman and Harrison [1983] and Harrison, Smith and Williams [1983], but tends to obscure our present concerns. Therefore we reduce the data by stages. First, in the next subsection we take a brief look at the time series of transacted (accepted) prices in each experiment. This overview provides a qualitative assessment of our principal predictions and a sound basis for subsequent statistical analysis. A more detailed "market commentary" that ferrets out and attempts to explain all anomalies is provided in Appendix 2.

The statistical analysis in the final subsection is performed on a data set that further reduces each sequence to a single observation. We then have only about 90 observations ( 6 Experiments x 5 Years x 3 markets) ${ }^{14}$, but our orthogonal experimental design allows considerable mileage from this smaller

${ }^{14}$ In futures experiments there are 4 markets if one counts Period $A$ and Period B trading separately for Period C certificates. 
data set. For Instance, a given Experiment 3 observation can be used in an evaluation of :

(a) the effect of event uncertainty, in a comparison with Experiment 1 ,

(b) the effect of futures markets, in a comparison with Experiment 4, and

(c) the effect of "insiders", In a comparison with Experiment 5.

Our statistical analysis will not be exhaustive, however; in the interest of brevity we will only present evidence bearing on our principal predictions.

\subsection{Overview}

Figures 1 through 6 chart the time series of transacted prices in each market experiment. The relevant theoretical equilibria for each Period are Indicated with dashed Iines, and summary statistics of transacted prices are shown at the bottom. Where applicable an ' $X$ ' refers to spot prices and a ' 0 ' to futures prices. Table 4 presents the observed period-end spot allocations, with the main theoretical predictions indicated by asterisks. (Period $\mathrm{C}$ and futures allocations are listed in Table Al in Appendix 3.)

Turning first to Figure 1, we see that in Experiment 1 (no event uncertainty, no futures market) Period A and B prices both tended to rise from values near PI in the first Market Year to near PF values by the end of Year 5. Period $C$ prices seemed to settle near their PF = PI value by the end of Year 2. Allocations also converged to the PF predictions at about the same rate, as indicated in Table 4. One could hardly hope for a clearer qualitative confirmation of our first prediction than this Experiment provides.

Figure 2 shows that futures transactions in Experiment 2 all occurred at prices at or slightly below the equilibrium level of $80 \$$, even in early Market Years. Period A and B prices and allocations are also very near PF values 


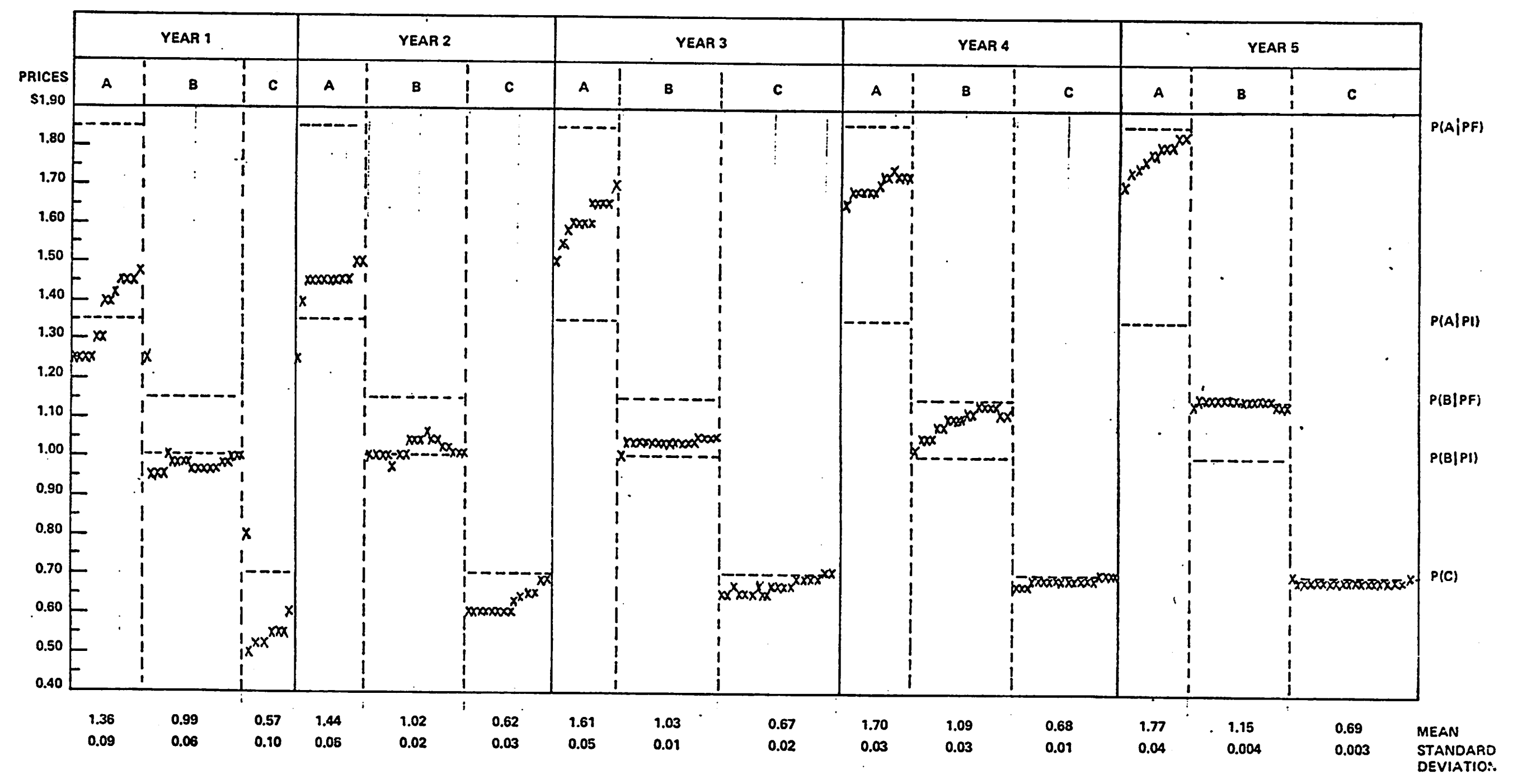

Figure 1: Observed Price Behavior - Experiment 1 


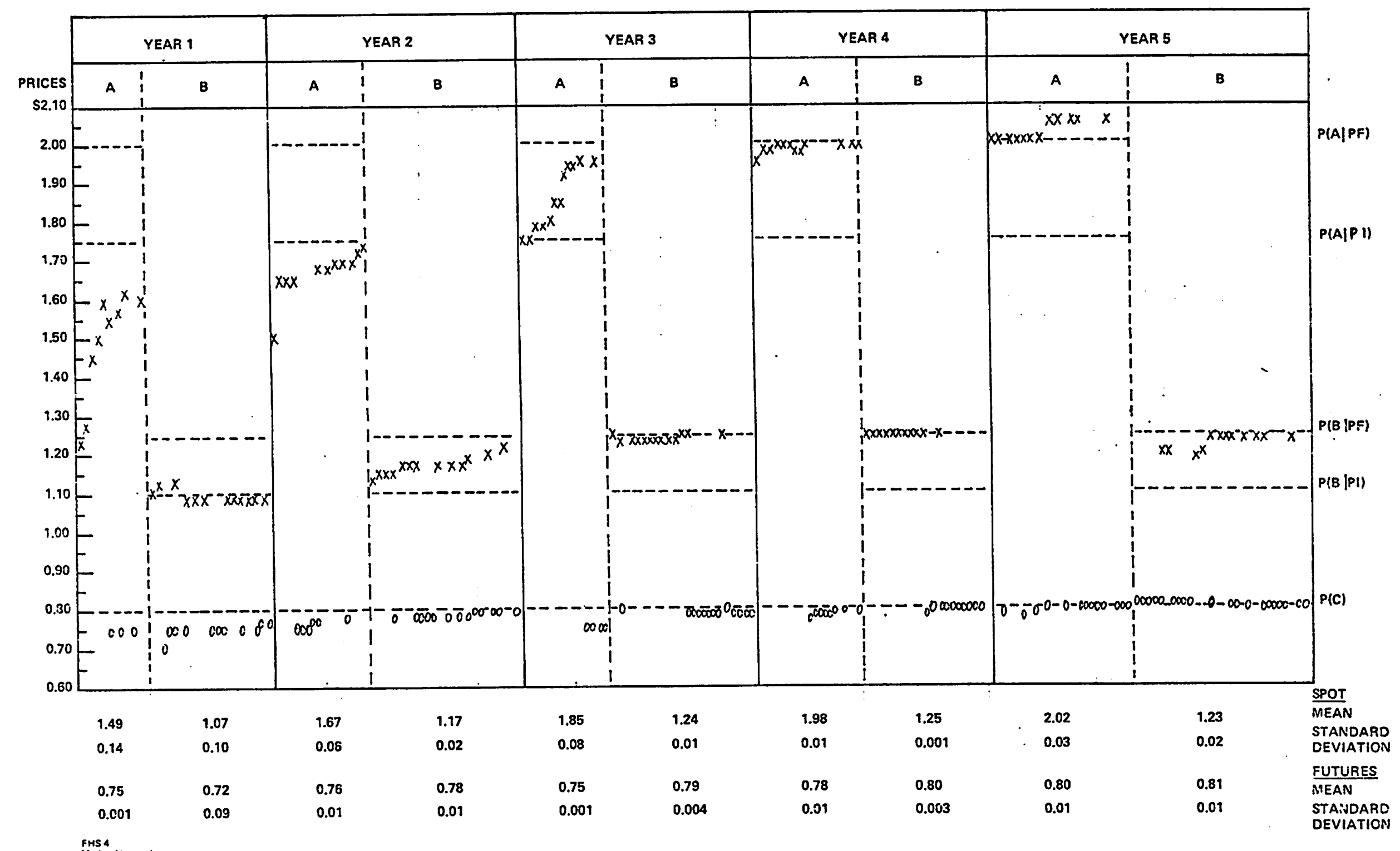

Figure 2: Observed Price Behavior - Experiment 2 


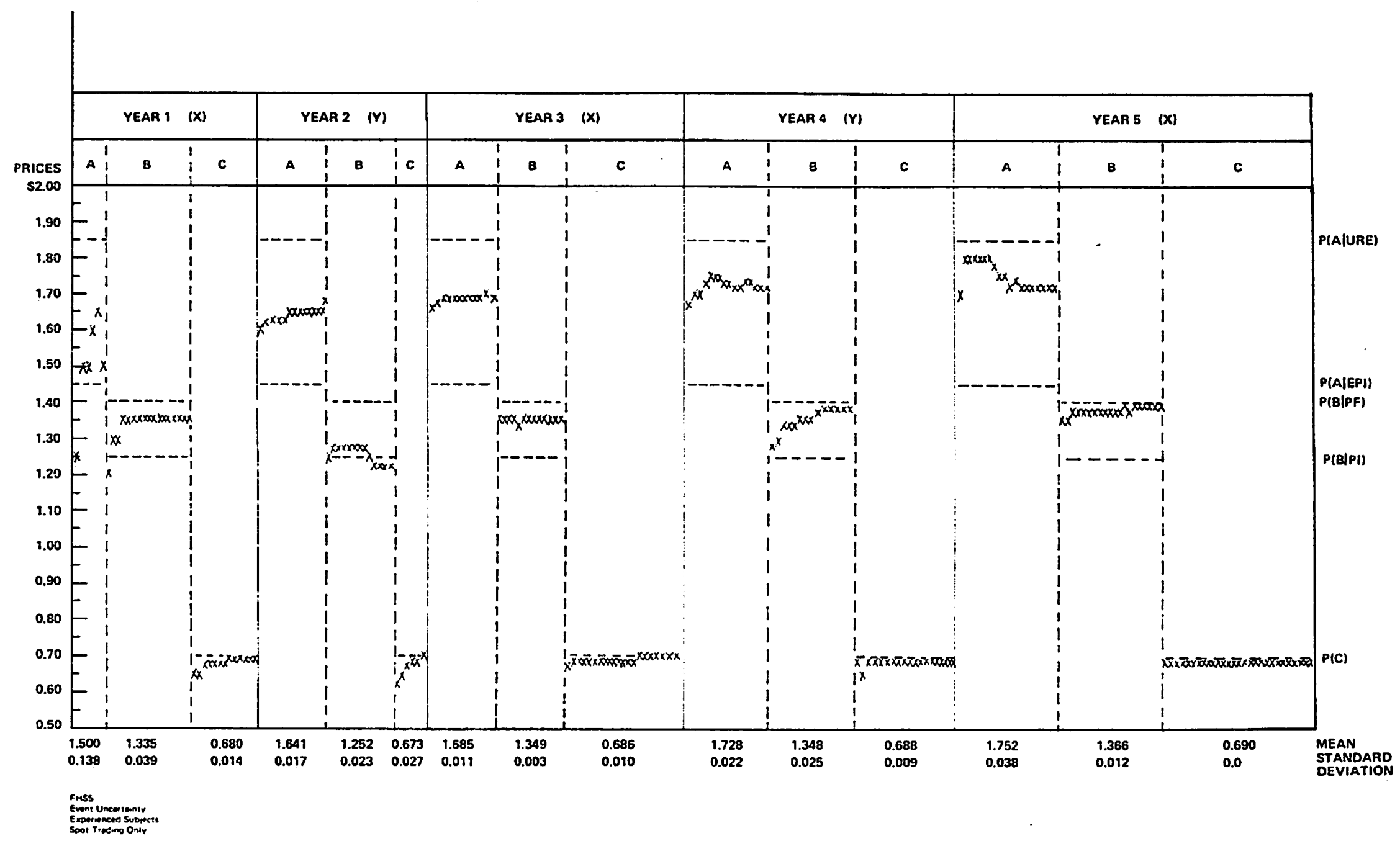

Figure 3: Observed Price Behavior - Experiment 3 


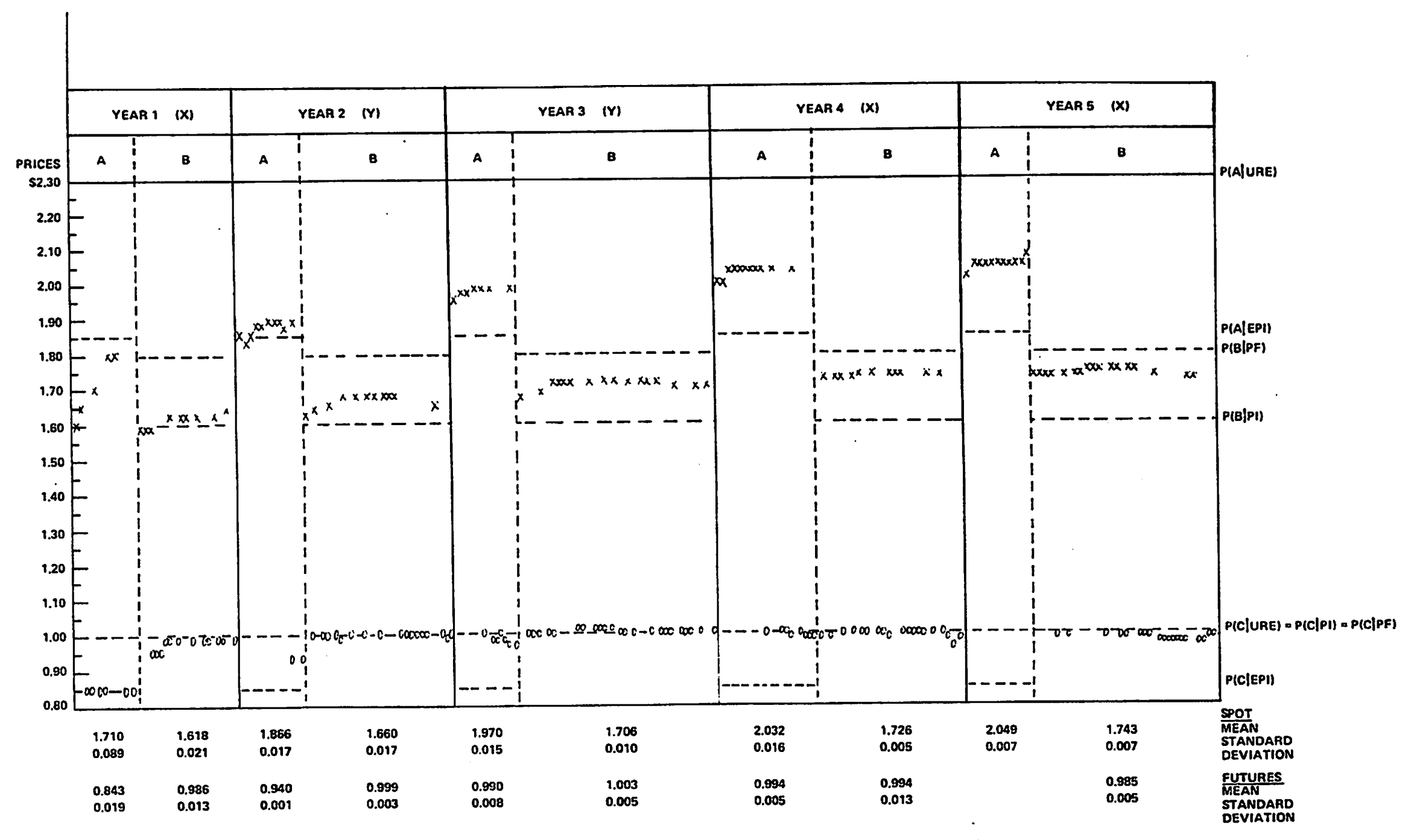

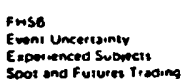

Figure 4: Observed Price Behavior - Experiment 4 


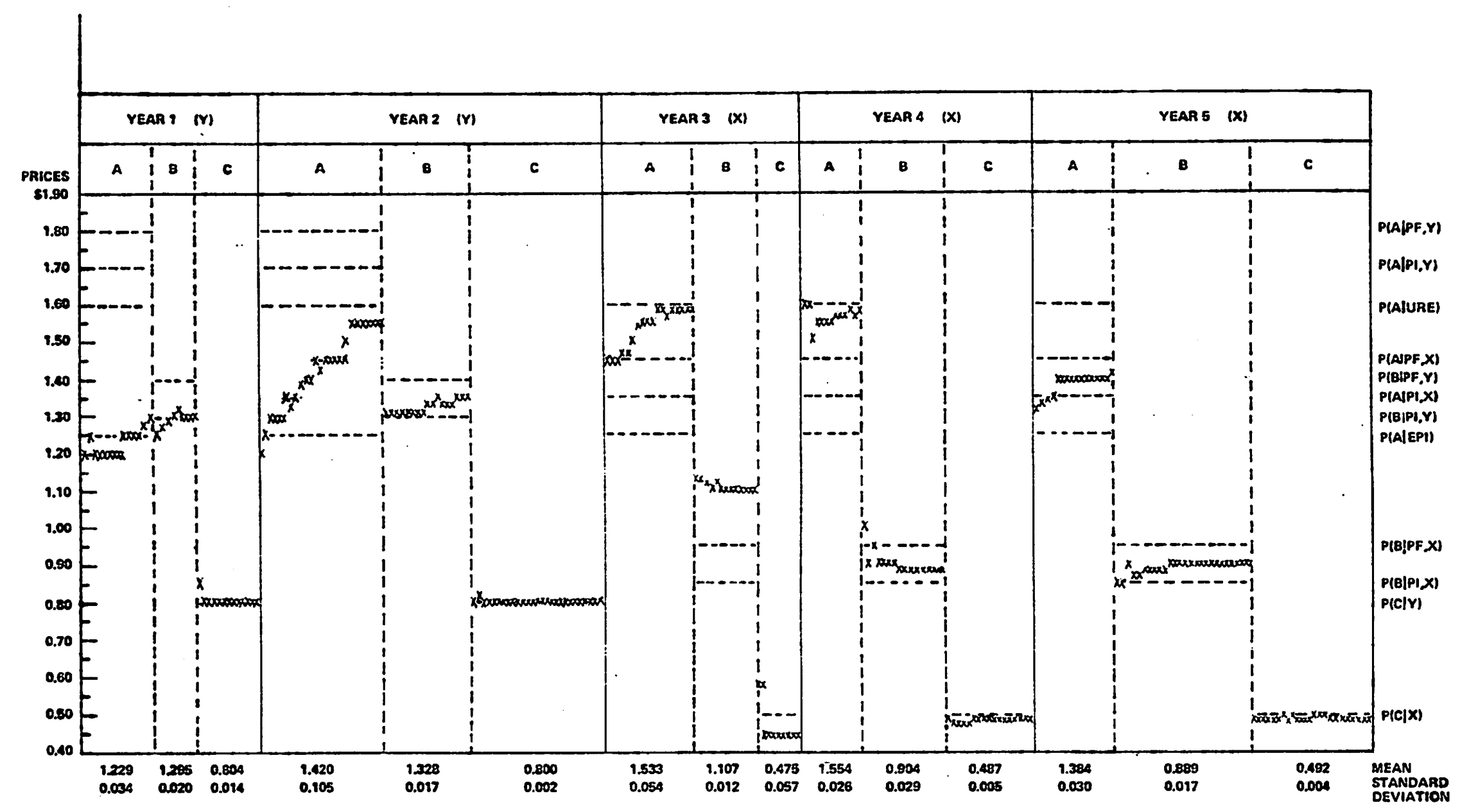

inse

Figure 5: Observed Price Behavior - Experiment 5 


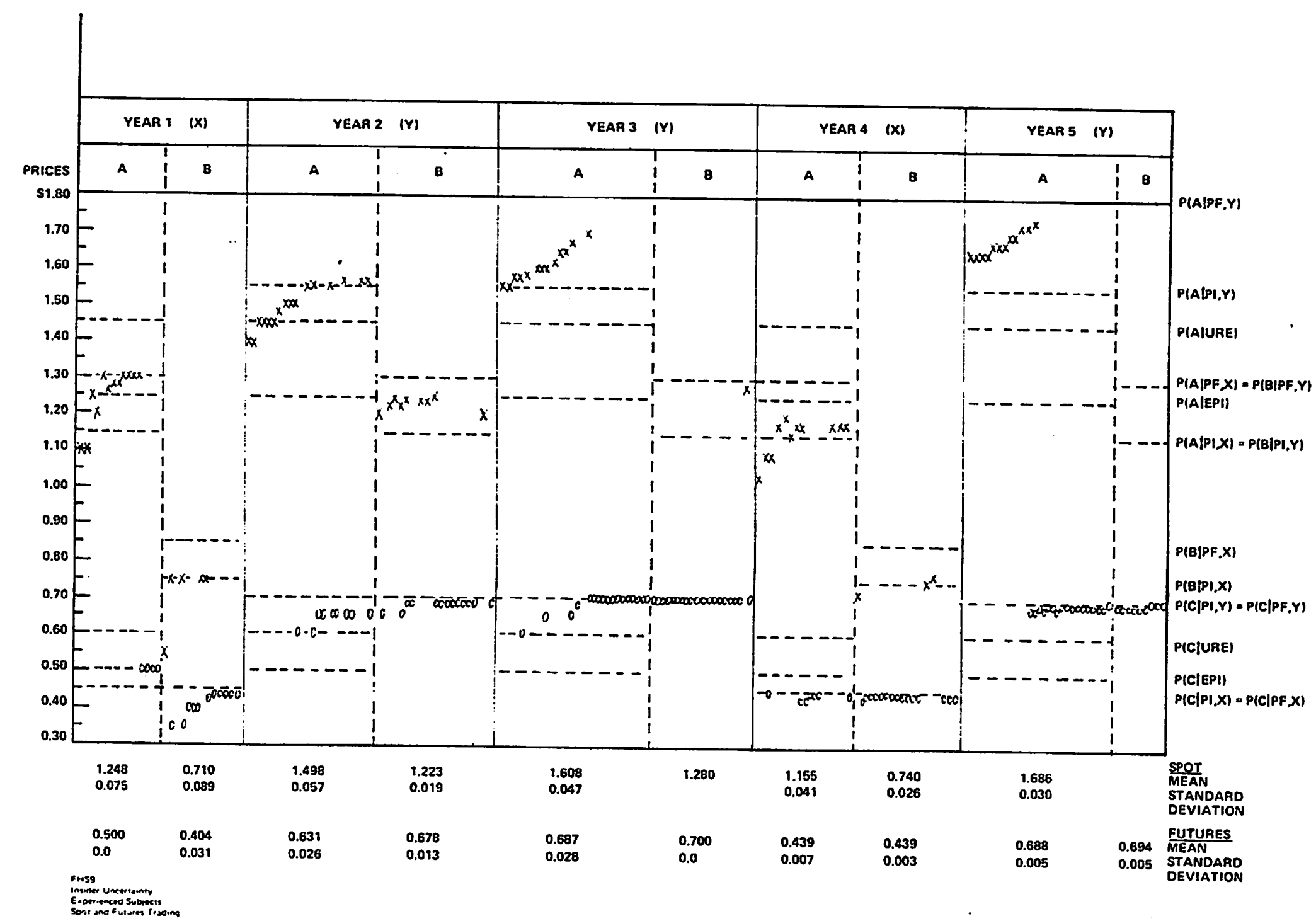

Figure 6: Observed Price Behavior - Experiment 6 
TABLE 4

Spot Certificate Allocations by Trader Type

Period A

$\frac{\text { Experiment } \quad \text { Yea }}{1}$

4

$\begin{array}{rrrr}1 & \mathrm{X} & 6 * * & 5 * \\ 2 & \mathrm{Y} & 11 * * & 5 * \\ 3 & \mathrm{Y} & 9 * * & 0 * \\ 4 & \mathrm{X} & 10 * * & 0 * \\ 5 & \mathrm{X} & 8 * * & 0 *\end{array}$

2

3

1
2
3
4
5

5

$\begin{array}{ll}1 & Y \\ 2 & Y \\ 3 & X \\ 4 & X \\ 5 & X\end{array}$

$\begin{array}{ll}- & 4 * \\ - & 0 * \\ - & 0 * \\ - & 0 * \\ - & 0 *\end{array}$

- $13 * / * *$

$-$

$-$

$=\frac{18 * / * k}{14 / * \star *}$

$\begin{array}{lr}\mathrm{X} & 5 * * \\ \mathrm{Y} & 14 * * \\ \mathrm{X} & 10 * * \\ \mathrm{Y} & 11 * * \\ \mathrm{X} & 18 * * \\ & \\ \mathrm{X} & 6 * * \\ \mathrm{Y} & 11 * * \\ \mathrm{Y} & 9 * * \\ \mathrm{X} & 10 * * \\ \mathrm{X} & 8 * *\end{array}$

$Y \quad 6$

$\mathrm{Y} \quad 0$

$\mathrm{X} \quad 14 * *$

$\mathrm{X} \quad 7 * *$

$\mathrm{X} \quad 3 * *$

6

0
0
0
0
13

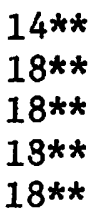

II

$\begin{array}{ll}1 & X \\ 2 & Y \\ 3 & \\ 4 & X \\ 5 & Y\end{array}$

$\begin{array}{lc}\mathrm{X} & 6 * * \\ \mathrm{Y} & 0 \\ \mathrm{Y} & 0 \\ \mathrm{X} & 13 * * \\ \mathrm{Y} & 0\end{array}$

III

I

Period B

III

$\begin{array}{rrrrr}0 & 3 * * & 1 & 14 * \\ 0 & 5 * * & 2 & 11 * \\ 0 & 16 * * & 2 & 0 * \\ 0 & 18 * * & 0 & 0 * \\ 0 & 18 * * & 0 & & 0 *\end{array}$


by Year 3.15

Recall that two states of the world were possible in Experiment 3, but by cholce of parameters Period B and C equilibrium prices were independent of realized state, while Period A dividends and most equilibrium allocations were state contingent. With this in mind, one is not surprised to see falrly rapid convergence of Period C prices and rather steady year-to-year movement of Period B prices from PI to PF values, desplte the yearly change in the "state of nature." Perlod A trading, thin and erratic with average prices near the EPI value in Year 1, becomes fairly steady by Years 4 and 5 with allocations precisely at their URE values and prices a little (5-15ф) below the URE level. One could attribute the low prices to risk aversion, Incomplete learning, or both.

Experiment 4 contains both expected and unexpected behavior. Futures prices behaved much as one might expect, rising from their EPI value of $85 \$$ In Period A of Year 1 to their URE and PF value of $\$ 1.00$ by Period $B$ of Year 2. Futures positions on the whole followed suit. Spot prices, on the other hand, were quite sluggish: average Period B prices rose each Year but did not complete the transition from PI to PF levels, while Period A prices only made about half of the transition from EPI to URE levels. As a consequence of these low Period A prices it was profitable for Type III traders to purchase spot even though they could not count on an $X$ realization of "nature." Evidently, Type I traders were slow to recognize significant expected profit opportunities arising from their Period A spot purchases.

${ }^{15}$ See Sections 4.1 .2 and 4.2 .2 of FHS for a discussion of two anomalies (one induced by the experimenters, the other by a "deviant" subject) in Year 5 of this Experiment; one can see that the effects are detectable but not large. 
A glance at Figure 5 discloses that the presence of insiders is not its only complication - parameters were chosen so that virtually all equilibrium prices and allocations were state-contingent. Period $\mathrm{C}$ prices and allocations tracked the equilibrium rather well with a minor exception in Year 3, the first $X$ Year. There is a strong hysteresis effect ${ }^{16}$ in Period $B$ prices of the same Year that dominates the otherwise evident rise from PI to PF levels. The same effect is present in Perlod A prices, which otherwise seem to move from EPI towards URE levels. This last interpretation; suggesting that inside information was not leaked, is supported by the fact that in Period $A$ of the last two years the majority of certificates were not held by Type I agents, as predicted in elther leakage equilibrium (PI or PF). A careful study of Figure 6, on the other hand, leads to the strong suspicion that inside information leaked out to the public rather quickly in Experiment 6. Futures prices in Period A consistently approached the informed $(P I=P F)$ equilibrium values of $45 \$$ in $X$ Years and $70 \phi$ in $Y$ Years, providing a good signal to non-insiders. Despite the fact that the state of nature changed three times in this experiment there is much less hysteresis in Period A and B spot prices than in Experiment 5, in which the state only changed once. In general the Period A spot price and allocation trends seem much more consistent with PF than the alternative equilibria, evidence in support of strong-form Informational efficiency.

16 We refer here to the tendency of the market to respond sluggishly to a change in the state of nature, so that previously established behavior prevalls for a while. See Harrison, Smith and Williams [1983] for a discussion of such phenomena. 


\subsection{Statistical Analysis}

\subsubsection{Convergence to Stronger-Form Informational Efficiency}

We now evaluate the prediction that our asset markets approach the stronger forms of informational efficiency by examining prices, allocations and profits. The traditional approach in the experimental literature has been to use a t-test on the sequence of transacted prices in a given trading period to see if the mean "differs significantly" from the theoretical equilibrium price. Once one recognizes that the transacted prices are not at ail analogous to I1d samples from a fixed population, 17 the meaning of such tests becomes quite obscure. Fortunately the very multiplicity of theoretical equilibria (for prices, allocations and profits) provides an attractive alternative: we can see which equilibrium concept gives us the best forecast. We are interested in the improvement or deterioration of the forecast performance of each concept, its overall accuracy, and its terminal accuracy in the final year of trading.

An appropriate measure of price convergence is the Root Mean Squared Deviation (RMSD) of transacted from forecast (equilibrium) price. Our prediction then is that RMSD's will decline (1.e., forecasts improve) over Market Years in both Periods $A$ and $B$ for stronger-form equilibrium prices (PF or URE), and that RMSD's will rise (1.e., forecasts deteriorate) for weaker-form equilibrium prices (PI or EPI). We also predict that the strong-form forecasts will be more accurate in the final year of trading and perhaps more accurate overall.

17 Bear in mind that each transaction provides new public information to the traders, so the hypothetical "population of potential prices" changes continually within the trading period. Harrison, Smith and Williams [1983] and Friedman and Harrison [1983] expand on this theme, which is also noted by FPPa (p. 549) when introducing their statistical tests. 
The data in Table 5 strongly support these predictions. In Period A of Experiment 1, for instance, the PI forecast error increases monotonically from $\$ 0.085$ in Year 1 to $\$ 0.427$ in Year 5, while the PF forecast error declines monotonically from $\$ 0.501$ to $\$ 0.082$. Simflarly, PF forecast errors for Period B decline steadily from $\$ 0.170$ to $\$ 0.005$ while PI errors, after dropping from $\$ 0.062$ in Year 1 to $\$ 0.022$ in Year 2, Increase steadily to $\$ 0.148$ in Year 5. The data for Experiment 2 tell a very similar story. Likewise, in Experiments 3 and 4 there is a striking improvement in the (strong-form) URE forecasts and a general deterioration in the (weak-form) EPI forecasts for Period A over successive Market Years of either realized state of nature. 18 The same behavior is evident with respect to the PF and PI forecasts for Period B.

One can make similar observations with respect to Experiments 5 and 6 , and for relevant Period $C$ prices, but the proliferation of numbers (e.g., four distinct forecasts for spot prices and three for futures prices in Period $A$ of Experiment 6) make this sort of analysis increasingly awkward. For that reason we present statistics in Table 6 that summarize the performance of each forecast for a given experiment. Each entry in the first ten columns of Table 6 is the posterior probability that a particular forecast is more 1ikely to Improve than to deteriorate from one Market Year (of a given state of nature)

${ }^{18}$ Our comments here and the statistical tests presented below generally pool results for each experiment over the two states of nature. Looking separately at the sequences of years for each state would strengthen our conclusions with respect to our primary predictions, but would reduce the sample size and lower the power of our tests. 
TABLE 5

Root Mean Squared Deviations From Equilibrium Price Predictions

\begin{tabular}{|c|c|c|c|c|c|c|c|c|c|c|c|c|}
\hline \multirow[b]{2}{*}{ - Experiment } & \multirow[b]{2}{*}{ Year } & \multirow[b]{2}{*}{ State } & \multicolumn{3}{|c|}{ Period A } & \multirow[b]{2}{*}{$\mathrm{PF}$} & \multicolumn{2}{|c|}{ Period B } & \multicolumn{4}{|c|}{ Period C } \\
\hline & & & EPI & PI & URE & & PI & PF & EPI & PI & URE & $\mathrm{PF}$ \\
\hline 1 & $\begin{array}{l}1 \\
2 \\
3 \\
4 \\
5\end{array}$ & $\begin{array}{l}- \\
- \\
- \\
-\end{array}$ & $\begin{array}{l}- \\
- \\
- \\
-\end{array}$ & $\begin{array}{l}0.085 \\
0.107 \\
0.266 \\
0.352 \\
0.427\end{array}$ & $\begin{array}{l}- \\
- \\
- \\
-\end{array}$ & $\begin{array}{l}0.501 \\
0.415 \\
0.245 \\
0.152 \\
0.082\end{array}$ & $\begin{array}{l}0.062 \\
0.022 \\
0.037 \\
0.096 \\
0.148\end{array}$ & $\begin{array}{l}0.170 \\
0.136 \\
0.116 \\
0.066 \\
0.005\end{array}$ & $\begin{array}{l}- \\
- \\
- \\
-\end{array}$ & $\begin{array}{l}* \\
* \\
* \\
* \\
*\end{array}$ & $\begin{array}{l}- \\
- \\
- \\
-\end{array}$ & $\begin{array}{l}0.158 \\
0.082 \\
0.036 \\
0.020 \\
0.010\end{array}$ \\
\hline 2 & $\begin{array}{l}1 \\
2 \\
3 \\
4 \\
5\end{array}$ & $\begin{array}{l}- \\
- \\
- \\
-\end{array}$ & $\begin{array}{l}- \\
- \\
- \\
-\end{array}$ & $\begin{array}{l}0.297 \\
0.104 \\
0.128 \\
0.232 \\
0.272\end{array}$ & $\begin{array}{l}- \\
- \\
-\end{array}$ & $\begin{array}{l}0.532 \\
0.342 \\
0.164 \\
0.022 \\
0.032\end{array}$ & $\begin{array}{l}0.155 \\
0.087 \\
0.010 \\
0.001 \\
0.031\end{array}$ & $\begin{array}{l}0.155 \\
0.087 \\
0.010 \\
0.001 \\
0.031\end{array}$ & $\begin{array}{l}- \\
- \\
- \\
-\end{array}$ & $\begin{array}{l}* \\
* \\
* \\
* \\
*\end{array}$ & $\begin{array}{l}- \\
- \\
- \\
-\end{array}$ & $\begin{array}{l}0.050 / 0.114 \\
0.044 / 0.018 \\
0.050 / 0.009 \\
0.019 / 0.003 \\
0.007 / 0.013\end{array}$ \\
\hline 3 & $\begin{array}{l}1 \\
2 \\
3 \\
4 \\
5\end{array}$ & $\begin{array}{l}X \\
Y \\
X \\
Y \\
X\end{array}$ & $\begin{array}{l}0.139 \\
0.202 \\
0.245 \\
0.289 \\
0.314\end{array}$ & $\begin{array}{l}- \\
- \\
- \\
-\end{array}$ & $\begin{array}{l}0.372 \\
0.209 \\
0.165 \\
0.124 \\
0.105\end{array}$ & $\begin{array}{l}- \\
- \\
- \\
-\end{array}$ & $\begin{array}{l}0.112 \\
0.031 \\
0.119 \\
0.120 \\
0.136\end{array}$ & $\begin{array}{l}0.075 \\
0.150 \\
0.051 \\
0.057 \\
0.036\end{array}$ & $\begin{array}{l}- \\
- \\
- \\
-\end{array}$ & $\begin{array}{l}* \\
* \\
* \\
* \\
*\end{array}$ & $\begin{array}{l}- \\
- \\
- \\
-\end{array}$ & $\begin{array}{l}0.024 \\
0.037 \\
0.017 \\
0.015 \\
0.010\end{array}$ \\
\hline 4 & $\begin{array}{l}1 \\
2 \\
3 \\
4 \\
5\end{array}$ & $\begin{array}{l}X \\
Y \\
Y \\
X \\
X\end{array}$ & $\begin{array}{l}0.161 \\
0.023 \\
0.121 \\
0.182 \\
0.199\end{array}$ & $\begin{array}{l}- \\
- \\
- \\
-\end{array}$ & $\begin{array}{l}0.595 \\
0.434 \\
0.330 \\
0.269 \\
0.251\end{array}$ & $\begin{array}{l}- \\
- \\
- \\
-\end{array}$ & $\begin{array}{l}0.027 \\
0.062 \\
0.107 \\
0.126 \\
0.143\end{array}$ & $\begin{array}{l}0.183 \\
0.141 \\
0.094 \\
0.074 \\
0.057\end{array}$ & $\begin{array}{c}0.019 \\
0.090 \\
0.140 \\
0.144 \\
-\end{array}$ & $\begin{array}{l}* \\
* \\
* \\
* \\
*\end{array}$ & $\begin{array}{c}0.158 \\
0.060 \\
0.013 \\
0.008 \\
-\end{array}$ & $\begin{array}{l}0.018 \\
0.003 \\
0.006 \\
0.014 \\
0.016\end{array}$ \\
\hline 5 & $\begin{array}{l}1 \\
2 \\
3 \\
4 \\
5\end{array}$ & $\begin{array}{l}\mathrm{Y} \\
\mathrm{Y} \\
\mathrm{X} \\
\mathrm{X} \\
\mathrm{X}\end{array}$ & $\begin{array}{l}0.039 \\
0.199 \\
0.288 \\
0.305 \\
0.138\end{array}$ & $\begin{array}{l}0.473 \\
0.298 \\
0.190 \\
0.205 \\
0.045\end{array}$ & $\begin{array}{l}0.348 \\
0.186 \\
0.068 \\
0.033 \\
0.193\end{array}$ & $\begin{array}{l}0.572 \\
0.394 \\
0.098 \\
0.107 \\
0.072\end{array}$ & $\begin{array}{l}0.019 \\
0.032 \\
0.257 \\
0.061 \\
0.043\end{array}$ & $\begin{array}{l}0.106 \\
0.074 \\
0.158 \\
0.054 \\
0.063\end{array}$ & $\begin{array}{l}- \\
- \\
- \\
-\end{array}$ & $\begin{array}{l}* \\
* \\
* \\
* \\
*\end{array}$ & $\begin{array}{l}- \\
- \\
- \\
-\end{array}$ & $\begin{array}{l}0.014 \\
0.002 \\
0.059 \\
0.013 \\
0.009\end{array}$ \\
\hline 6 & $\begin{array}{l}1 \\
2 \\
3 \\
4 \\
5\end{array}$ & $\begin{array}{l}X \\
Y \\
Y \\
X \\
Y\end{array}$ & $\begin{array}{l}0.077 \\
0.229 \\
0.337 \\
0.127 \\
0.412\end{array}$ & $\begin{array}{l}0.121 \\
0.076 \\
0.074 \\
0.040 \\
0.139\end{array}$ & $\begin{array}{l}0.215 \\
0.073 \\
0.165 \\
0.289 \\
0.238\end{array}$ & $\begin{array}{l}0.089 \\
0.307 \\
0.197 \\
0.151 \\
0.118\end{array}$ & $\begin{array}{c}0.089 \\
0.076 \\
0.130 \\
0.024 \\
-\end{array}$ & $\begin{array}{c}0.161 \\
0.079 \\
0.020 \\
0.112 \\
-\end{array}$ & $\begin{array}{l}0.000 \\
0.133 \\
0.189 \\
0.062 \\
0.188\end{array}$ & $\begin{array}{l}* \\
* \\
* \\
* \\
*\end{array}$ & $\begin{array}{l}0.075 \\
0.061 \\
0.115 \\
0.137 \\
0.113\end{array}$ & $\begin{array}{l}0.050 / 0.055 \\
0.073 / 0.025 \\
0.030 / 0.0 \\
0.013 / 0.011 \\
0.013 / 0.007\end{array}$ \\
\hline
\end{tabular}

NOTES: 1) An asterisk for the PI RMSE of Period $C$ prices indicates that the statistics are the same as the PF RMSE for that year (i.e., the PI price prediction equals the PF price prediction).

2) A slash in the PF futures price statistics for experiments 2 and 6 indicate the Period A RMSE/Period B RMSE.

3) In experiment 4 the EPI and URE RMSE for the futures prices reflect Period A prices only. 
to the next. 19 Hence values above 0.5 for strong-form forecasts and below 0.5 for weak-form forecasts are evidence in favor of our prediction.

Table 6 confirms the conclustons drawn so far from Table 5. For Instance, the steady Improvement noted in the PF forecasts for Experiment 1 yield postertor probabilities of .823 for both Period A (column 4) and Period B (column 6), and .895 for the pooled data (column 10), while the corresponding entries for the PI forecasts (columns 2, 5 and 8) yleld probabilities for forecast Improvement of only .177, .261, and .095 respectively. The results for Experiments 2-4 are generally similar, with pooled (Period A + Period B) probabilities of strong-form forecast improvement of $.848, .848$, and .895 respectively.

Recall that there are four competing equilibrium forecasts in Experiments 5 and 6. In Experiment 5 there is a general improvement in the PI, URE and PF forecasts for Period A, and no significant improvement in either of the forecasts (PI and PF) for Period B. The pooled data for both periods therefore reflects the Period A outcome, which allows us to dismiss only the EPI forecast (probability $=.261<.5$ ). It 18 interesting to note that in Experiment 6 the "leakage forecasts" PI and PF dominate the corresponding "no leakage forecasts" EPI and URE, supporting the conclusion that leakage of inside Information occurred in Experiment 6.

${ }^{19}$ Each change In forecast performance in successive Market Years of a given state of nature in a given Experiment is viewed as an outcome from a discrete binomial distribution, with a forecast improvement being viewed as a "success" and any non-improvement a "fallure." The diffuse prior distribution adopted for the probability of a "success," $\theta$, was the Bayes-Laplace uniform prior on the unit interval. In Table 6 we report the posterior probability that $\theta$ exceeds one-half. See Zellner [1971; pp. 38/40; p. 316, fn. 37] for a complete discussion of these Bayesian procedures. A similar measure of forecast improvement is implied by a test used by Plott and Sunder [1982; p. 683], although their test was applied to individual price changes whereas ours is applied to changes in average forecast performance (RMSD) over each year. 
The alternative forecasts do not differ for Period $C$ spot prices, nor for futures prices arising in Period B trading. The futures ("Period C") prices arising in Period A of Experiment 4 still follow the predicted pattern: according to Table 5 the EPI forecasts deteriorated and the URE forecasts Improved in each case. In Experiment 6 we have three alternatives to consider (EPI, URE and PF). A ranking of their forecast improvement provides additional support for our prediction, with the PF forecast Improving more than the URE forecast, which in turn Improved more than the EPI forecast. 20

Despite their impressive showing with respect to forecast improvement, the strong-form forecasts do not appear to dominate their weak-form counterparts with respect to overall accuracy. In columns 11-13 of Table 6 we report the probability that the yearly RMSD's for the stronger-form forecast are on average lower than those for the corresponding weaker-form forecast. 21 These probabilities exceed .5, suggesting that the stronger-form forecast is more accurate overall, for the pooled (Period A + Perlod B) sample In only three of the six Experiments (\$2, 3, and 6).

${ }^{20}$ Table 6 does not show the probabilities of improvement associated with these remarks concerning futures prices in Period A. In Experiment 4 they were 0.214 (EPI) and 0.786 (URE), and in Experiment 6 they were 0.261 (EPI), 0.5 (URE) and 0.739 (PF). Pooling the results for these two experiments we obtain probabilities 0.118 (EPI), 0.798 (URE) and 0.882 (URE in Experiment 4 and PF in Experiment 5, the strong-form equilibria).

${ }^{21}$ These probabilities are obtained from a (one-tail) non-parametric MannWhitney test for the "slippage problem." See Hoel [1971; pp. 310/318] for a formal discussion. We state the test outcomes in terms of the probability of the hypothesis that slippage has occurred in favor of the stronger-form equilibrium forecasts; the alternative hypothesis is that both samples arise from the same population. The weaker-form (stronger-form) Period A equilibria used for this test in Experiments 1 through 6 are, respectively; PI (PF), PI (PF), EPI (URE), EPI (URE), EPI (PF) and EPI (PF). The relevant equilibria in Period $B$ are, of course, PI and PF in each experiment. 
This negative result is not too surprising considering the relatively few repetitions of each state of nature in our Experiments. Given the absence of any generally accepted models of learning and price adjustment it has become common in the experimental literature to focus on comparative terminal accuracy. Of course we have only one observation for each state in each experiment when we examine relative forecast errors by this criterion, so we cannot report probabilities here. Instead we report the ratio of the weakerform RMSD to the stronger-form RMSD in the last two columns of Table 6 (top six lines only). 22 An entry of at least 1.0 is favorable for our prediction that the strong-form foreasts are superior; we observe such entries in every case for the Experiments in which the terminal year is the fifth (\#1 and \#2), and in a majority of cases in which the terminal year is the second or third repetition (Experiments $\$ 3-5$, which have $X$ and $Y$ states of nature).

We may summarize our findings on price convergence by examining the statistics in Table 6 obtained by pooling data across all Experiments (1ine 9, marked "all"). Our prediction that strong-form equilibria dominate with respect to forecast improvement is strongly confirmed by the posterior probabilities for both Period A and Perlod B; the pooled probabilities (columns $7-10$ ) of $99.4 \%$ for PF and URE versus $1.7 \%$ and $14.7 \%$ for EPI and PI could hardly be more conclusive. The prediction that the strong-form equilibria provide more accurate forecasts overall, on the other hand, is definitely not supported; this prediction has an overall probability of only $37.1 \%$ (column 13). Finally, the probabilities of $96.8 \%$ and $93.8 \%$ (columns 14 and 15) lead us to accept the hypothesis that the strong-form equilibria

22The terminal $X$-years and $Y$-years for Experiments 3, 4, 5 and 6 are separated by a slash in Table 6. 
provide superior price forecasts in the terminal year.

We now turn to an analysis of allocations. For each trading Period and relevant forecast we can obtain the number of certificates "misallocated" and process these numbers just as we did the corresponding price RMSD's. Table 4 may be used to infer these misallocations, which are listed in Table A2 in Appendix 3. Again we predict that the strong-form forecast misallocations w111 decline over Market Years and that those for the weak-form forecasts will increase. We are also interested in the comparative accuracy of the alternative forecasts.

Table 6 presents the results of tests on our allocation predictions that are comparable to those just discussed for the price predictions. Pooling data over all experiments and both Periods $A$ and $B$, we attach $96.8 \%$ confidence to our prediction about strong-form forecast improvement (this refers to the PF forecast; the corresponding URE confidence level is 90.2\%). Contrast this with the mere $9.9 \%$ confidence we can attach to EPI-forecast improvement (and $5.7 \%$ confidence to PI-forecast improvement). The only case in which the confidence of a weaker-form forecast improvement exceeds that attached to the stronger-form is in Period A of Experiment 5, but the confidence levels are generally low in this case for all of the forecasts. As for overall forecast accuracy, with the exception of Experiment 2 (in which the various allocation forecasts are observationally equivalent) and Perlod B of Experiment 5, we find that the strong-form forecasts always dominate; the pooled probability of $95.1 \%$ in favor of this prediction seems quite conclusive. We obtain even stronger results for terminal Year accuracy, with pooled probabilities of strong-form superiority of $98.2 \%$ and $99.8 \%$ for Periods A and B respectively.

A final measure of convergence considered is the error in forecasting trading profits. Table 7 presents actual trading profits in each Market Year 
TABLE 6

Significance of Forecast Improvement and Comparative Accuracy

\begin{tabular}{|c|c|c|c|c|c|c|c|c|c|c|c|c|c|c|c|c|c|}
\hline \multirow[b]{3}{*}{ Meissure } & \multirow[b]{3}{*}{ Experiment } & \multicolumn{10}{|c|}{ Forecast Improvement } & \multicolumn{3}{|c|}{$\begin{array}{c}\text { Overall } \\
\text { Forecast Accuracy } \\
\end{array}$} & \multicolumn{3}{|c|}{$\begin{array}{c}\text { Terminai } \\
\text { Forecast Accur. }\end{array}$} \\
\hline & & \multicolumn{4}{|c|}{ Period $\Lambda$} & \multicolumn{2}{|c|}{ Period B } & \multicolumn{4}{|c|}{ Period A and Period B } & \multirow[b]{2}{*}{ Period A } & \multirow[b]{2}{*}{ Period B } & \multirow{2}{*}{$\begin{array}{c}\text { Period A } \\
\text { and } \\
\text { Period B }\end{array}$} & \multirow[b]{2}{*}{ Period A } & \multirow[b]{2}{*}{ Period B } & \\
\hline & & EPI & PI & URE & PF & PI & PF & EPI & PI & URE & PF & & & & & & \\
\hline \multirow[t]{9}{*}{ Prices } & 1 & - & 0.177 & - & 0.823 & 0.261 & 0.823 & - & 0.095 & - & 0.895 & 0.421 & 0.210 & 0.264 & 5.2 & 29.6 & \\
\hline & 2 & - & 0.261 & - & 0.739 & 0.739 & 0.739 & - & 0.5 & - & 0.848 & 0.5 & 0.5 & 0.602 & 8.5 & 1.0 & \\
\hline & 3 & 0.177 & - & 0.823 & - & 0.261 & 0.5 & 0.095 & - & 0.848 & - & 0.790 & 0.726 & 0.803 & $2.9 / 2.3$ & $3.8 / 2.1$ & \\
\hline & 4 & 0.261 & - & 0.823 & - & 0.177 & 0.823 & 0.095 & - & 0.895 & - & 0.0 & 0.345 & 0.038 & $0.8 / 0.4$ & $2.5 / 1.1$ & \\
\hline & 5 & 0.261 & 0.739 & 0.739 & 0.739 & 0.5 & 0.5 & 0.287 & 0.713 & 0.713 & 0.713 & 0.421 & 0.075 & 0.218 & $1.9 / 0.7$ & $0.5 / 0.4$ & \\
\hline & 6 & 0.261 & 0.739 & 0.5 & 0.739 & 0.639 & 0.639 & 0.383 & 0.798 & 0.617 & 0.798 & 0.726 & 0.343 & 0.534 & $0.8 / 3.5$ & $0.2 / 6.5$ & \\
\hline & $1,3 \& 5$ & 0.095 & 0.287 & 0.904 & 0.904 & 0.172 & 0.828 & 0.037 & 0.121 & 0.963 & 0.963 & 0.574 & 0.267 & 0.491 & 0.952 & 0.845 & \\
\hline & $2,4 \& 6$ & 0.152 & 0.5 & 0.848 & 0.848 & 0.398 & 0.878 & 0.157 & 0.417 & 0.952 & 0.952 & 0.186 & 0.362 & 0.283 & 0.726 & 0.790 & \\
\hline & al1 & 0.035 & 0.328 & 0.965 & 0.965 & 0.174 & 0.945 & 0.017 & 0.147 & 0.994 & 0.994 & 0.313 & 0.429 & 0.371 & 0.968 & 0.938 & $\underset{\rho}{\omega}$ \\
\hline \multirow[t]{9}{*}{ Allocations } & 1 & - & 0.177 & - & 0.823 & 0.177 & 0.823 & - & 0.095 & - & 0.895 & 0.996 & 0.992 & 1.0 & - & - & \\
\hline & 2 & - & 0.261 & - & 0.261 & 0.739 & 0.739 & - & 0.5 & - & 0.5 & 0.5 & 0.5 & 0.5 & - & - & \\
\hline & 3 & 0.261 & - & 0.739 & - & 0.261 & 0.739 & 0.095 & - & 0.848 & - & 0.972 & 0.992 & 0.999 & - & - & \\
\hline & 4 & 0.177 & - & 0.5 & - & 0.261 & 0.5 & 0.095 & - & 0.5 & - & 0.996 & 0.996 & 1.0 & - & - & \\
\hline & 5 & 0.5 & 0.261 & 0.261 & 0.261 & 0.739 & 0.739 & 0.713 & 0.5 & 0.5 & 0.5 & 0.726 & 0.345 & 0.602 & - & - & \\
\hline & 6 & 0.739 & 0.5 & 0.261 & 0.739 & 0.261 & 0.739 & 0.5 & 0.287 & 0.5 & 0.848 & 0.726 & 0.992 & 0.962 & - & - & \\
\hline & $1,3 \& 5$ & 0.287 & 0.095 & 0.5 & 0.713 & 0.172 & 0.943 & 0.328 & 0.058 & 0.807 & 0.942 & 1.0 & 0.996 & 0.998 & 0.952 & 0.972 & \\
\hline & $2,4 \& 6$ & 0.287 & 0.287 & 0.287 & 0.5 & 0.310 & 0.828 & 0.106 & 0.328 & 0.807 & 0.807 & 0.881 & 0.996 & 0.938 & 0.790 & 0.972 & \\
\hline & all & 0.193 & 0.058 & 0.328 & 0.672 & $0.136^{\circ}$ & 0.976 & 0.099 & 0.057 & $0 . \dot{902}$ & 0.968 & $0.934^{\circ}$ & 0.996 & 0.951 & 0.982 & 0.998 & \\
\hline
\end{tabular}


TABLE 7

Percent Deviations of Actual Profits from Predicted Equilibrium Profit

\begin{tabular}{|c|c|c|c|c|c|c|}
\hline \multirow[b]{2}{*}{ Experiment } & \multirow[b]{2}{*}{ Year } & \multirow[b]{2}{*}{ State } & \multicolumn{4}{|c|}{ Equilibrium Concept } \\
\hline & & & EPI & PI & URE & $\mathrm{PF}$ \\
\hline 1 & $\begin{array}{c}1 \\
2 \\
3 \\
4 \\
5 \\
\text { a11 }\end{array}$ & $\begin{array}{l}- \\
- \\
- \\
- \\
-\end{array}$ & $\begin{array}{l}- \\
- \\
- \\
- \\
-\end{array}$ & $\begin{array}{l}158 \\
285 \\
250 \\
300 \\
300 \\
259\end{array}$ & $\begin{array}{l}- \\
- \\
- \\
- \\
-\end{array}$ & $\begin{array}{r}-35 \\
-4 \\
-12 \\
0 \\
0 \\
-10\end{array}$ \\
\hline 2 & $\begin{array}{c}1 \\
2 \\
3 \\
4 \\
5 \\
\text { a11 }\end{array}$ & $\begin{array}{l}- \\
- \\
- \\
- \\
-\end{array}$ & $\begin{array}{l}- \\
- \\
- \\
- \\
-\end{array}$ & $\begin{array}{r}17 \\
28 \\
28 \\
-8 \\
9 \\
15\end{array}$ & $\begin{array}{l}- \\
\overline{-} \\
- \\
\overline{-}\end{array}$ & $\begin{array}{l}-20 \\
-12 \\
-12 \\
-36 \\
-25 \\
-21\end{array}$ \\
\hline 3 & $\begin{array}{c}1 \\
2 \\
3 \\
4 \\
5 \\
\text { X-years } \\
\text { Y-years } \\
\text { a11 }\end{array}$ & $\begin{array}{l}X \\
Y \\
X \\
Y \\
X \\
- \\
- \\
-\end{array}$ & $\begin{array}{r}61 \\
227 \\
95 \\
241 \\
38 \\
65 \\
234 \\
112\end{array}$ & $\begin{array}{l}- \\
\overline{-} \\
- \\
\overline{-} \\
- \\
-\end{array}$ & $\begin{array}{r}-35 \\
-7 \\
-21 \\
-3 \\
-44 \\
-33 \\
-5 \\
-23\end{array}$ & $\begin{array}{l}- \\
- \\
- \\
- \\
- \\
- \\
-\end{array}$ \\
\hline 4 & $\begin{array}{c}1 \\
2 \\
3 \\
4 \\
5 \\
\text { X-years } \\
\text { Y-years } \\
\text { a11 }\end{array}$ & $\begin{array}{l}X \\
Y \\
Y \\
X \\
X \\
- \\
- \\
-\end{array}$ & $\begin{array}{r}10 \\
113 \\
123 \\
-33 \\
54 \\
10 \\
118 \\
46\end{array}$ & $\begin{array}{l}- \\
- \\
- \\
- \\
- \\
- \\
-\end{array}$ & $\begin{array}{r}-42 \\
-4 \\
0 \\
-65 \\
-19 \\
-42 \\
-2 \\
-27\end{array}$ & $\begin{array}{l}- \\
- \\
- \\
- \\
- \\
- \\
-\end{array}$ \\
\hline 5 & $\begin{array}{c}1 \\
2 \\
3 \\
4 \\
5 \\
\text { X-years } \\
\text { Y-years } \\
\text { all }\end{array}$ & $\begin{array}{l}Y \\
Y \\
X \\
X \\
X \\
- \\
- \\
-\end{array}$ & $\begin{array}{r}422 \\
483 \\
40 \\
-5 \\
-11 \\
452 \\
8 \\
107\end{array}$ & $\begin{array}{r}-5 \\
6 \\
-2 \\
-33 \\
-37 \\
1 \\
-24 \\
-11\end{array}$ & $\begin{array}{r}23 \\
37 \\
-41 \\
-60 \\
-63 \\
30 \\
-55 \\
-26\end{array}$ & $\begin{array}{l}-20 \\
-10 \\
-24 \\
-49 \\
-52 \\
-15 \\
-42 \\
-28\end{array}$ \\
\hline 6 & $\begin{array}{c}1 \\
2 \\
3 \\
4 \\
5 \\
\text { X-years } \\
\text { Y-years } \\
\text { all }\end{array}$ & $\begin{array}{l}X \\
Y \\
Y \\
X \\
Y \\
- \\
- \\
-\end{array}$ & $\begin{array}{r}-72 \\
241 \\
275 \\
-29 \\
300 \\
-50 \\
272 \\
90\end{array}$ & $\begin{array}{r}-55 \\
33 \\
46 \\
12 \\
56 \\
-22 \\
45 \\
29\end{array}$ & $\begin{array}{r}-81 \\
71 \\
87 \\
-53 \\
100 \\
-67 \\
86 \\
10\end{array}$ & $\begin{array}{r}-73 \\
-15 \\
-6 \\
-34 \\
0 \\
-54 \\
-7 \\
-19\end{array}$ \\
\hline
\end{tabular}


(defined as total payments to subjects less transactions commissions and dividends that would accrue if no trade took place) as a percentage deviation from theoretical trading profits arising in each equilibrium ${ }^{23}$ (again excluding implied commissions and profit from no-trade). The strong-form equilibria once more dominate. Average forecast error is only $10 \%$ for PF versus 259\% for PI in Experiment 1, and $21 \%$ versus $15 \%$ in Experiment 2; it 1s $23 \%$ for URE versus $112 \%$ for EPI in Experiment 3, and $27 \%$ verus $46 \%$ in Experiment 4. Simllarly in Experiments 5 and 6 we find that, conditional on leakage occurring or not occurring, the stronger-form forecasts win (compare PF and PI for "leakage," and URE and EPI otherwise). Pooling over all experiments we have computed the confidence of profit forecast improvement as $19.3 \%$ for EPI, $10.6 \%$ for PI, $32.8 \%$ for URE, and $67.2 \%$ for PF. The confidence In the hypothesis that the stronger-form forecasts are more accurate over all Years exceeds $99.9 \%$

\subsubsection{The Informational Role of Futures Markets}

We now evaluate our second major prediction, that futures markets stabilize spot prices and enhance efficlency.

A direct measure of price volatility is the Coefficient of Variation (CV) of transacted prices. 24 Table 8 11sts the probability of a lower $\mathrm{CV}$

23 We measure theoretical profits by evaluating the payouts to traders if they held the theoretically predicted allocations and recelved the theoretically predicted dividends. Thus each of these profits is simply the predicted Period A equilibrium price times the aggregate number of certificates (eighteen in our experiments). Hence we are actually measuring allocational efficlency, with misallocations weighted according to how much they reduce gains from trade.

${ }^{24}$ The CV is just the ratio of the standard deviation to the mean. The objective of this transformation is to normalize the standard deviation in order to correct for parameter differences across experiments. The $\mathrm{CV}$ measures are presented in Table $A 3$ in Appendix 3, and were derived from the data listed in Figures 1 through 6. 
TABLE 8

Effect of Futures Markets on Spot Price Variability

\begin{tabular}{|c|c|c|c|c|c|c|}
\hline & Measure & $\begin{array}{l}\text { Experimental } \\
\text { Design }\end{array}$ & $\begin{array}{l}\text { Experiments } \\
\text { Compared }\end{array}$ & Period A & Period B & $\begin{array}{c}\text { Period A } \\
\text { and } \\
\text { Period } B\end{array}$ \\
\hline \multirow[t]{5}{*}{$\mathrm{CV}$} & & Market Uncertainty & 1 and 2 & 0.5 & 0.5 & 0.602 \\
\hline & & Event Uncertainty & 3 and 4 & 0.845 & 0.845 & 0.947 \\
\hline & & Insider Uncertainty & 5 and 6 & 0.274 & 0.206 & 0.047 \\
\hline & & Pooled (Overall) & $(1,3,5)$ and $(2,4,6)$ & 0.653 & 0.702 & 0.720 \\
\hline & & Pooled (Final Years) & $(1,3,5)$ and $(2,4,6)$ & 0.889 & 0.421 & 0.803 \\
\hline \multirow[t]{4}{*}{$\mathrm{CV}$} & Improvement & Market Uncertainty & 1 and 2 & 0.5 & 0.0 & 0.333 \\
\hline & & Event Uncertainty & 3 and 4 & 0.667 & 0.667 & 0.757 \\
\hline & & Insider Uncertainty & 5 and 6 & 0.833 & 0.667 & 0.971 \\
\hline & & Pooled & $(1,3,5)$ and $(2,4,6)$ & 0.845 & 0.925 & 0.944 \\
\hline
\end{tabular}

NOTES: Measures of each $\mathrm{CV}$ and $\mathrm{CV}$ Improvement are listed in Tables A3 and A4, respectively; the probabilities shown are based on a Mann-Whitney test. 
for spot prices and, separately, the probability of a greater CV Improvement in the experiments with a futures market than in those without one. 25 with pooled data we accept the hypothesis of a lower CV with futures markets at the $65.3 \%$ confidence level in Period $A$ and a $70.2 \%$ confidence level in Period B. Pooling the final Year data across all Experiments and Periods we obtain an $80.3 \%$ confidence level for this hypothesis. Note, however, the sharp contrast in the results between the Event Uncertainty and Insider Uncertainty designs. Our results support with even more confidence the hypothesis that the presence of futures markets increases the 1mprovement in CV $(94.4 \%$ confidence overal1). This result obtains for both Event Uncertainty and Insider Uncertainty designs.

Given the strength of our conclusion that the presence of futures markets reduces spot price variability, we should clarify the relationship between our results and the seemingly contrary results reported in FPPb. It can be shown (see Table A5 In Appendix 3) that futures markets in the FPPb study led to a significantly lower $\mathrm{CV}$ in spot prices in the terminal trading period (79.4\% confidence) and to increased CV improvement ( $72.2 \%$ confidence). On the other hand, the evidence is (overwhelmingly) contrary to the hypothesis that FPPb futures markets reduced the CV over all trading periods (only $0.3 \%$ confidence), and in essence it is this last finding that they emphasize. Note, however, that they employ the joint treatment variable of "futures

${ }^{25}$ A (one-tail) non-parametric Mann-Whitney test is used, as in columns 11-15 of Table 6 . The probability measures show the confidence attached the hypothesis that the presence of futures markets lowers the $\mathrm{CV}$ of spot prices or increases the proportional CV improvement. The latter probabilities are based on data shown in Table A4 of Appendix 3. 
markets and trader inexperience", 26 and do not isolate "futures markets" or "Inexperience" as single treatments. The results of FHS, in which these two treatments were separately identified, suggest that each has qualitatively different effects on spot price variablity (with a higher CV being associated with "Inexperience" and a lower CV with "futures markets"; see Table 7 of FHS). We therefore conclude that the FPPb data are not really contrary to ours, and are Indeed in some respects supportive.

A summary measure of market trading efficiency is the profit earned relative to the stronger-form profit prediction (excluding, as before, commissions and no-trade profits). Table 9 shows the confidence we attach to the hypotheses that efficiency is greater in the presence of futures markets and, separately, that the improvement in efficiency is also greater with futures markets. Efficiency appears to be enhanced with futures markets in the Insider Uncertainty design ( $72.6 \%$ confidence), while there is no detectable effect under Event Uncertainty and Indeed a reduction in efficiency under Market Uncertainty (see FHS for a detalled analysis of the comparative behavior of Experiments 1 and 2). The pooled results are similarly mixed, with the overall probability of $41.0 \%$ slightly unfavorable and the final-years probability of $65.5 \%$ slightly favorable to our prediction. The results are much more conclusive with respect to the effect of futures markets on the Improvement in trading efficiency. Our prediction is accepted with $84.5 \%$ confidence overall, and $83.3 \%$ confidence in each of the Event Uncertainty and

26 The experiments reported in FPPb employed a strong intertemporal inseparability in preferences (i.e., the marginal value of a certificate held in Period B depended strongly on how many certificates had been held in Period $A$, and vice versa). It is not clear to us whether this unusual design feature reflects any important real-world phenomenon, or whether it has an important effect on spot price variability. 
TABLE 9

Effect of Futures Markets on Trading Efficiency

Experimental

Design

\section{Experiments}

Compared
Probability of Greater Efficiency

\section{Trading}

Efficiency

Market Uncertainty
Event Uncertainty
Insider Uncertainty
Pooled (Overal1)
Pooled (Final Years)

1 and 2

0.048

3 and 4

0.5

5 and 6

0.726

$(1,3,5)$ and $(2,4,6)$

0.410

Pooled (Final Years)

$(1,3,5)$ and $(2,4,6)$

0.655

Improvement

Market Uncertainty

$I$ and 2

0.5

in Trading

Event Uncertainty

3 and 4

0.833

Insider Uncertainty

5 and 6

0.833

Pooled

$(1,3,5)$ and $(2,4,6)$

0.845

NOTES: Measures of Trading Efficiency and Improvement in Trading Efficiency are Iisted in Tables 7 and A6, respectively; the probabilities shown are based on a MannWhitney test. 
Insider Uncertainty designs.

A more subtle effect of futures markets appears in connection with the comparison of strong and semi-strong forms of efficiency in Experiments 5 and 6. From Table 6, one can see that the semi-strong price forecast (URE) did less well in the presence of a futures market (Experiment 6) than in its absence (Experiment 5) with repect to forecast improvement, while the strongform price forecast (PF) performed equally well in the two experiments with respect to improvement and notably better In Experiment 6 with respect to overall accuracy. Similar comparisons for allocation forecasts also suggest that futures markets enhance the performance of strong-form forecasts relative to that of semi-strong form forecasts.

A final plece of evidence is relevant in this connection. In Table 10, we compare the average trading profits of insiders to non-insiders in Experiments 5 and 6.27 One can see the average insider did indeed earn higher profits than the average outsider in every Market Year. More interestingly, however, insiders did notably less well when a futures market was present: a Mann-Whitney test allows us to associate $72.6 \%$ confidence with this claim.

\footnotetext{
${ }^{27}$ Profits were normalized as usual by deducting securtty (no-trade) profit and ignoring transaction commissions. For outsiders, security profits in Period $A$ are measured by taking the dividends prevailing in the worst possible state of nature and multiplying them by initial certificate endowments. Security profits in Periods $B$ and $C$ are calculated using the actual dividends, since the state of nature is revealed (this is the measure of security, or no-trade, profits employed in Table 7). Security profits for insiders could be measured in exactly the same manner, and we show the results of doing this in the first column. An alternative measure that reflects their inside knowledge evaluates endowments in Period A (and B and C) using actual dividends.
} 
TABLE 10

Insider Profits as a Ratio of Average Outsider Profits

Insider Security Profit Measure

\begin{tabular}{ccccc}
\cline { 3 - 4 } Experiment & Year & State & Same as Outsiders & Different to Outsiders \\
\hline \multirow{2}{*}{5} & 1 & $Y$ & 3.89 & 4.26 \\
& 2 & $Y$ & 1.57 & 1.71 \\
& 3 & $X$ & 3.49 & 3.86 \\
& 4 & $X$ & 1.18 & 1.30 \\
& 5 & $X$ & 1.62 & 1.78 \\
& 1 & $X$ & 1.23 & 1.32 \\
& 2 & $Y$ & 1.34 & 1.69 \\
& 3 & $Y$ & 3.16 & 4.03 \\
& 4 & $X$ & 1.37 & 3.47 \\
& 5 & $Y$ & 2.80 & 34 \\
\hline
\end{tabular}




\section{Conclusions}

Our experimental results support the following broad conclusions.

1) Market outcomes evolve over time towards strong-form informationally efficient equilibria. This finding is quite robust to the presence or absence of futures markets and/or event uncertainty, and is evident in our analysis of prices, allocations and profits.

2) The presence of futures markets tends to stabilize spot prices. As measured by the coefficient of variation, transacted spot prices were typically less volatile in experiments that employed futures markets than in companion experiments with no futures markets. The effect was particularly strong in the Event Uncertainty design, and was significant overall.

3) The presence of futures markets tends to speed the evolution of markets to more informationally efficient equilibria, at least in the presence of event uncertainty. The greater complexity and shorter trading time confronting our traders in experiments with futures markets seemed to impair market efficiency at first, but efficiencies in the terminal Year were comparable to those in the corresponding experiments with no futures markets.

4) Futures markets promote the "leakage" of insider information. When a futures market was present we found that insiders earned significantly lower profits, and that "leakage" equilibrium prices were better forecasts of actual transacted prices. In particular, strong-form informationally efficient forecasts clearly outperformed semi-strong-form forecasts only when a futures market operated.

These conclusions must, of course, be confirmed by other experimenters before they can be regarded as fully established. In some ways our experimental design is the most complex so far employed, and it is comforting that our first conclusion corresponds so well to the findings of most other 
experimenters. On the other hand we have noted that our second and third conclusions differ in some respects from the findings of FPPb and others, while our last conclusions seems entirely new. New experiments are called for, and it seems particularly important to find designs that minimize the possibility of trader confusion and information overload. Computer mediated markets should be very helpful in this respect. 


\section{References}

Arrow, K. J., and Hahn, F., General Competitive Analysis (San Francisco: Holden Day, 1971).

Bray, M., "Futures Trading, Rational Expectations, and the Efficient Markets Hypothesis," Econometrica, 49 (1981), 575-96.

Cox, C.C., "Futures Trading and Market Information," Journal of Political Economy, 84 (1976), 1215-37.

Easley, D., and Ledyard, J. O., "A Theory of Price Formation and Exchange in Oral Auctions," Discussion Paper No. 461, The Center for Mathematical Studies in Economics and Management Science, Northwestern University, January 1983 (revised).

Fama, E. F., "Efficient Capital Markets: A Review of Theory and Empirical Work," Journal of Finance, 25 (1970), 383-417.

Forsythe, R, Palfrey, T.R., and Plott, C.R., "Asset Valuation in an Experimental Market," Econometrica, 50 (1982a), 537-67. , _ _ and __ Futures Markets and Informational

Efficiency: A Laboratory Examination," GSIA Working Paper No. 11-82-83, (Carnegie-Mellon University, 1982b). Friedman, D., "Continuous Double Auctions and Price Formation in Asset Markets," unpublished manuscript, Department of Economics, UCLA, 1982. , and Harrison, G. W., "Price Formation in Experimental Asset

Markets: A Bayesian Approach," unpublished manuscript, Department of Economics, UCLA, 1983. and Salmon, J.W., "The Informational Role of Futures

Markets: Some Experimental Evidence," in M.E. Streit (ed.) Futures Markets -- Modelling, Managing and Monitoring Futures Trading (Oxford: Basil 
Blackwe11, 1983).

Grether, D. M., and Wilde, L. L., "Consumer Cholce and Information: New

Experimental Evidence on the Information Overload Hypothesis," Social

Science Working Paper No. 459, Division of the Humanities and Social

Sclences, California Institute of Technology, 1982.

Grossman, S.J., "On the Efficiency of Competitive Stock Markets Where Traders

Have Diverse Information," Journal of Finance, 31 (1977a), 573-85..

, "The Existence of Futures Markets, Noisy Rational Expectations,

and Informational Externalities," Review of Economic Studies, 44 (1977b), 431-49.

, "Further Results on the Informational Efficiency of Competitive

Stock Markets," Journal of Economic Theory 19 (1978), 81-101. , and Stiglitz, J.E., "Information and Competitive Price Systems,"

American Economic Review (Papers and Proceedings), 66 (1976), 246-53. , and , "On the Impossibility of Informationally Efficient

Markets," American Economic Review 70 (1980), 393-409.

Hardy, C.0., Risk and Risk Bearing (Chicago: University of Chicago Press, 1940).

Harrison, G. W., Smith, V. L., and Williams, A. W., "Learning Behavior in

Experimental Auction Markets," unpublished manuscript, Department of

Economics, University of Western Ontario, 1983.

Plott, C.R., and Sunder, S., "Efficiency of Experimental Security: Markets with

Insider Information: An Application of Rational-Expectations Models,"

Journal of Political Economy 90 (1982), 663-98. , and , "Rational Expectations and the Aggregation of

Diverse Information in Laboratory Security Markets," Social Science Working Paper No. 463, Division of the Humanities and Social Sciences, California 
Institute of Technology, 1983.

Svensson, L.E.0., "Sequences of Temporary Equilibria, Stationary Point Expectations and Pareto Efficiency," Journal of Economic Theory, 13 (1976), 169-83.

Vickrey, W., "Counterspeculation, Auctions and Competitive Sealed Tenders," Journal of Finance, 16 (1961), 8-37.

Zeliner, A., An Introduction to Bayesian Inference in Econometrics . New York: Wiley, 1971). 